\title{
Speed Segmentation on Exchanges: Competition for Slow Flow
}

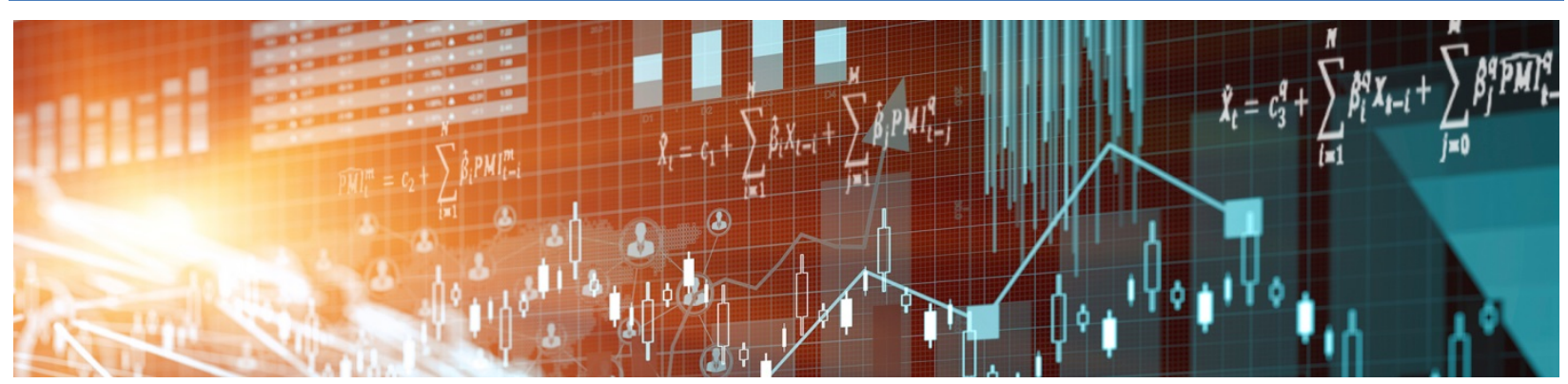

by Lisa Anderson, Emad Andrews, Baiju Devani, Michael Mueller and Adrian Walton 
Bank of Canada Staff Working Paper 2018-3

January 2018

\title{
Speed Segmentation on Exchanges: Competition for Slow Flow
}

\author{
by \\ Lisa Anderson, ${ }^{1}$ Emad Andrews, ${ }^{1}$ Baiju Devani, ${ }^{1}$ Michael Mueller ${ }^{2}$ and \\ Adrian Walton ${ }^{2}$ \\ 1 Investment Industry Regulatory Organization of Canada \\ ${ }^{2}$ Financial Markets Department \\ Bank of Canada \\ Ottawa, Ontario, Canada K1A 0G9 \\ mmueller@bankofcanada.ca \\ awalton@bankofcanada.ca
}




\section{Acknowledgements}

We would like to thank David Cimon, Darcey McVanel, Jean-Sebastien Fontaine, Corey Garriott, Victoria Pinnington, Alex Taylor, Doug Harris, Andrew Kriegler, Kevin McCoy, Ryan Riordan, and participants at the Bank of Canada market microstructure workshop for their valuable feedback. 


\begin{abstract}
In 2015, TSX Alpha, a Canadian stock exchange, implemented a speed bump for marketable orders and an inverted fee structure as part of a redesign. We find no evidence that this redesign impacted market-wide measures of trading costs or contributed appreciably to segmenting retail order flow away from other Canadian venues with a maker-taker fee structure. This suggests that Alpha attracts already-segmented flow from venues with fee structures other than maker-taker. Some heavy users of Alpha trade off improvements in fill rates and execution size against mildly larger effective spreads and price impacts. These heavy users also utilize larger market orders and fewer spray orders.
\end{abstract}

Bank topics: Financial markets; Market structure and pricing

JEL codes: G14, G24

\title{
Résumé
}

La bourse canadienne Alpha TSX a instauré en 2015, dans le cadre de l'adoption d'un nouveau modèle, un délai de traitement ( "ralentisseur ») des ordres négociables et un barème de droits inversé. Rien n'indique que ce nouveau modèle a eu une incidence sur les mesures des coûts de transaction à l'échelle du marché ou qu'il a contribué notablement à segmenter les flux d'ordres de détail en les détournant d'autres plateformes de négociation canadiennes qui appliquent un modèle de tarification teneur-preneur. Ce constat donne à penser qu'Alpha attire des flux déjà segmentés en provenance de plateformes utilisant des barèmes de droits autres que le modèle précité. Certains gros utilisateurs d'Alpha opèrent un arbitrage entre, d'une part, une hausse des taux d'exécution et de la taille des ordres et, d'autre part, une légère accentuation des écarts effectifs et de l'incidence sur les cours. Ces gros utilisateurs exécutent aussi des ordres au mieux de plus grande taille et ont moins recours à la méthode d'acheminement des ordres par éparpillement.

Sujets : Marchés financiers ; Structure de marché et fixation des prix Codes JEL : G14, G24 


\section{Non-technical summary}

Several stock exchanges have recently implemented a "speed bump," a delay between the receipt of an order and its execution. Speed bumps can reduce the speed advantage of fast, sophisticated traders, who may then choose to avoid the speed bump exchange. Discouraging certain types of traders from transacting on particular venues and thereby concentrating them on others is referred to as segmentation. Segmentation has been shown to have the potential to increase transaction costs in security markets.

In this paper, we study the redesign of a Canadian equity exchange, TSX Alpha, which on September 21, 2015, adopted a speed bump for marketable orders. Along with the speed bump, TSX Alpha introduced a minimum order size above which limit orders are exempt from the speed bump, and changes to its fee structure for order execution. Using a detailed regulatory dataset from the Investment Industry Regulatory Organization of Canada (IIROC), we find that the Alpha redesign did not meaningfully contribute to further segmentation in Canada.

Consistent with not observing a significant change in segmentation, market-wide measures of trading costs in Canada do not change materially, relative to either their past levels or a matched control sample of US stocks. While standard market-wide liquidity measures change little, execution size-the average quantity traded when two orders are matched-increases market-wide by around $5 \%$ after the Alpha relaunch. Alpha's minimum order sizes therefore enable both buy-side (institutional) and retail (individual) investors to execute against larger limit orders. On Alpha alone, execution size nearly doubles from 150 to 260 shares, consistent with Alpha being the driver behind this effect.

To better understand how users of Alpha adapt to the venue's new features, we contrast outcomes for heavy users of Alpha with those for light users. Heavy users of Alpha are those traders who take liquidity on Alpha relatively often, while light users are those who take liquidity on Alpha less often. Following Alpha's redesign, both retail and buy-side heavy users have their orders filled more frequently, and order execution sizes increase. For the buy-side users, we find a small increase in some transaction cost measures. However, buy-side traders may still find it beneficial to route order flow to Alpha for other reasons. Trading off marginal execution costs for larger execution size and higher fill rates allows a position to be built in fewer orders. This reduces the complexity and operational cost of the transaction, as well as the risk of adverse price movements over the course of a sequence of trades.

We find evidence of a shift in trading behaviour among heavy users of Alpha. In line with a preference for higher fill rates and larger execution sizes, the order-to-trade ratios of heavy buy-side users decrease when building large positions, and heavy buy-side users submit larger market orders relative to light users. In addition, we find that heavy users reduce the fraction of multi-venue spray orders significantly relative to light users, which is consistent with reacting to the mechanics of Alpha's speed bump. Since the speed bump is a randomized delay, a sprayed order may arrive at Alpha too early, causing liquidity providers to adjust their quotes on other venues, or a sprayed order may arrive too late, by which time liquidity providers on Alpha have already adjusted their quotes. The observation that heavy users utilize fewer spray orders also suggests that some traders value having their orders filled without spraying, which may include Alpha-sourced liquidity, over spray-routed fills, which do not include Alpha-sourced liquidity. 


\section{Introduction}

Several stock exchanges have recently implemented a "speed bump," a delay between the receipt of an order and the execution of its instructions. ${ }^{2}$ Empirically, it is not yet well understood how a speed bump affects market liquidity and traders' behaviours and execution strategies. Speed bumps can reduce the speed advantage of certain types of fast, sophisticated traders. The effect that these traders have on market quality is widely debated: on the one hand, fast traders can improve price discovery and hence liquidity, while on the other hand their ability to act quickly on new information may increase the risk of adverse selection to market makers. ${ }^{3}$ If, for instance, these fast traders avoid the speed bump exchange and route to other venues instead, adverse selection for market makers on the non-speed bump venues can increase, and thereby affect market-wide liquidity and hence trading costs for investors. Similarly, adverse selection on other venues can increase if the speed bump venue attracts low adverse selection flow such as retail order flow from other venues. Speed bumps can thus act as segmentation devices that separate different types of traders across venues, similar to other innovations such as dark pools and maker-taker pricing schemes. ${ }^{4}$

We study the redesign of TSX Alpha Exchange (Alpha), which, on September 21, 2015, adopted a speed bump along with two other new features: a minimum order size which, if met, exempts passive limit orders from the speed bump, and an inverted fee structure. ${ }^{5,6}$ Using a granular regulatory dataset from the Investment Industry Regulatory Organization of Canada (IIROC), we find that, on average, the Alpha redesign did not segment retail order flow away from other venues. Using the volume of market orders from retail traders as a measure of uninformed order flow, we find that other venues with maker-taker trading fee structures increased their share of total retail flow after the Alpha redesign. These makertaker venues include Chi-X and the Toronto Stock Exchange (TSX), Canada's largest stock exchange. These venues also increased their retail component, the fraction of venues' total volume that is retail. However, the retail component on other inverted venues decreased slightly following Alpha's redesign. This suggests that Alpha is competing for retail order flow with other inverted venues, those that seek to attract market orders, but not with maker-taker venues. ${ }^{7}$ Alpha therefore caters to order flow that was already segmented. These findings go counter to theoretical work by Brolley and Cimon (2017), who

\footnotetext{
${ }^{2}$ Examples include TSX Alpha and Aequitas NEO in Canada and IEX and NYSE American in the US.

${ }^{3}$ See Menkveld (2016) for a comprehensive literature review on fast traders' impact on market quality.

${ }^{4} \mathrm{Zhu}$ (2013) shows that the addition of dark pools can enhance price discovery while reducing liquidity, and Malinova and Park (2015) find that the introduction of maker-taker fees on the Toronto Stock Exchange did not affect transaction costs for liquidity demanders, but the use of aggressive orders increased, especially by retail traders.

${ }^{5}$ The speed bump is a randomized delay of one to three milliseconds. It is not applied to all orders on Alpha; orders marked "post only" and of size greater than specified minimum volumes are exempt from the speed bump. ${ }^{6}$ As a result of the redesign, Alpha became an unprotected trading venue, eliminating any explicit regulatory obligation for orders to be routed to the exchange to comply with the Order Protection Rule. At the same time, Alpha migrated to a new trading platform, Quantum XA, and Alpha's parent, the TMX Group, decommissioned another trading venue, TMX Select.

${ }^{7}$ At the time of the Alpha's redesign, of the thirteen equity trading venues in Canada, three had inverted fee structures.
} 
show that speed bumps can segment traders by type; in their model, uninformed traders use the speed bump exchange while informed traders avoid it.

Consistent with Alpha not absorbing sizeable retail flow from other venues, market-wide measures of trading costs in Canada do not change materially, relative to either their past levels or to a matched control sample of US stocks. Quoted depth and price impact remain relatively unchanged while marketwide effective spreads display mild improvements. Our findings of Alpha's redesign having a neutral to slightly positive impact on liquidity are in line with empirical work that finds that speed differentials can be good or neutral for liquidity. Brogaard et al. (2015) examine investment in speed on a Swedish stock exchange. The authors find it is primarily the market makers in their sample who invest in speed and that market quality improves following the resulting upgrade in speed. Our findings are also consistent with a deterioration of liquidity when liquidity takers have a speed advantage (Biais, Foucault and Moinas (2015); Foucault, Kozhan and Tham (2017); Shkilko and Sokolov 2016). Since Alpha's speed bump diminishes the speed advantage of liquidity takers but not liquidity providers, the difference in our findings is natural. Our results contrast with those in Chen et al. (2017), who attribute deterioration in market liquidity to increased market segmentation after the Alpha relaunch. We note that using the trading desk IDs available uniquely in our dataset allows us to more reliably identify low adverse selection (retail) order flow.

While standard market-wide liquidity measures change little, execution size-the average quantity traded when two orders are matched-increases market-wide by around $5 \%$ after the Alpha relaunch. Alpha's minimum order sizes enable both buy-side (institutional) and retail (individual) investors to execute against larger limit orders. On Alpha alone, execution size almost doubles from 150 to 260 shares, consistent with Alpha being the driver behind this effect.

We interpret Alpha's redesign as a strategy to compete for market orders. Two of the redesign features incentivize market orders to be routed to Alpha: the inverted fee schedule and the minimum limit order sizes. ${ }^{8}$ In an inverted fee structure, the exchange attracts order flow by paying rebates for executed market orders. Prior work shows that fees can affect order routing behaviour: Battalio, Corwin and Jennings (2016) document that differences between exchanges' fee schedules can influence brokers' routing decisions, while Malinova and Park (2015) note that following the introduction of maker-taker pricing on the TSX, retail traders in particular use aggressive orders more frequently. In a theory model, Cimon (2016) demonstrates that brokers route marketable orders to exchanges with lower liquiditydemand fees. In his model, a segmentation effect also obtains: the volume of uninformed orders at these venues increases, thereby lowering the risk of adverse selection for limit orders posted there.

Without the speed bump, inverted fees and the increased minimum depth created by the minimum limit order sizes would also attract market orders from traders using latency-sensitive strategies. These traders may include high-speed arbitrageurs or liquidity takers who attempt to execute against quoted

\footnotetext{
${ }^{8}$ Inverted exchange fees, sometimes called "taker-maker," pay rebates for executed market orders and charge fees for executed limit orders. By contrast, "maker-taker" exchange fees pay rebates for executed limit orders and charge fees for executed market orders.
} 
depth on multiple venues simultaneously, using "spray orders." ${ }^{9}$ Fast traders who take liquidity can impose adverse selection risks on liquidity providers and can discourage liquidity supply (Brolley and Cimon 2017; Biais, Foucault and Moinas 2015). We therefore interpret the speed bump as a mechanism to compensate liquidity suppliers: the speed bump creates a short time window during which liquidity providers have the ability to cancel their orders, possibly ahead of large market-priced orders originating from traders that pose a high risk of adverse selection and that could move the market. The speed bump gives liquidity providers on Alpha more certainty that they trade with order flow posing relatively low adverse selection risk.

To better understand how users of Alpha adapt to the venue's new features, we contrast outcomes for heavy users of Alpha with those for light users. Heavy users of Alpha are those traders who take liquidity on Alpha relatively often, while light users are those who take liquidity on Alpha less often. Since routing to Alpha is voluntary, we view the heavy users as those able to successfully integrate Alpha into their routing tables and take advantage of the liquidity posted there.

Following Alpha's redesign, both retail and buy-side heavy users experience significantly higher order fill rates and larger execution sizes. For the buy-side users, price impact and effective spreads deteriorate slightly, relative to light users. Implementation shortfall for buy-side traders does not change significantly between the two groups, which is consistent with our findings on market-wide liquidity. We interpret this finding as follows: liquidity providers may be able to discern the larger adverse selection risk in the buy-side flow over a sequence of trades, which leads to an adjustment of spreads and price impact. However, buy-side traders still find it beneficial to route order flow to Alpha. Trading off marginal execution costs (price impact and effective spread) for larger execution size and higher fill rates is appealing because it allows a position to be built in fewer orders. This reduces the complexity and operational cost of the transaction, as well as the risk of adverse price movements over the course of a sequence of trades. ${ }^{10}$

We find evidence of a shift in trading behaviour among heavy users of Alpha that is consistent with their execution quality following Alpha's redesign. In line with a preference for higher fill rates and larger execution sizes, heavy buy-side users' order-to-trade ratios decrease when building large positions, relative to light users, and they submit larger market orders. In addition, we find that heavy users reduce the fraction of sprayed orders significantly relative to light users, which is consistent with reacting to the mechanics of Alpha's speed bump. Since the speed bump is a randomized delay, a sprayed order may arrive at Alpha too early, causing liquidity providers to adjust their quotes on other venues, or a sprayed order may arrive too late, by which time liquidity providers on Alpha may have already adjusted their quotes. ${ }^{11}$ The observation that heavy users utilize fewer spray orders also suggests that some traders

\footnotetext{
${ }^{9}$ For example, RBC's Thor algorithm; see "High-frequency traders changing the game," Marjo Johne, The Globe and Mail, 8 February 2011.

${ }^{10}$ Larger execution sizes also reduce "ticket costs." Tickets are created when individual orders are executed against each other; the number of limit orders required to fill a market order determines the number of tickets. Both buyside and retail brokers pay a fixed cost per ticket to back-office data service providers, which can be substantial. ${ }^{11}$ Van Kervel (2015) shows that in a setting with fast and slow traders, market makers' limit order cancellations following a trade are efficient and reflect the information content of the trade.
} 
value non-spray-routed fills, which may include Alpha-sourced liquidity, over spray-routed fills which do not include Alpha-sourced liquidity.

\section{Data and institutional details}

We use a sample of regulatory data that all Canadian equity trading venues (see Table 1 ) provide to IIROC, the self-regulatory organization for the investment industry in Canada. Prior to the redesign of Alpha, there were 13 exchanges and alternative trading systems (ATS) in Canada. On the redesign date of Alpha, the TMX Group decommissioned another trading venue, TMX Select, leaving 12 equity trading venues. Table 1 lists the trading venues, their fee structures in the periods before and after the redesign of Alpha, and whether the trading venue is dark or has a speed bump. When Alpha was redesigned, in addition to the implementation of a speed bump, the venue's fee structure changed from maker-taker to inverted, and Alpha migrated to a new trading platform, Quantum XA. As a result of the speed bump, Alpha became an unprotected trading venue for the purposes of the Order Protection Rule, ${ }^{12}$ which eliminates any explicit regulatory obligation for orders to be routed to New Alpha.

$$
\text { [***Table } 1 \text { about here***] }
$$

Alpha's speed bump is a randomized 1 to 3 millisecond delay applied to all incoming order messages with the exception of minimum-sized order messages which are entered with a "post only" marker. ${ }^{13}$ Stock-specific minimum size requirements are assigned to post-only orders at the start of the trading day and are based on price and volume characteristics. Minimum sizes range from 500 to 20,000 shares during our sample period. ${ }^{14}$

Our sample consists of stocks that were part of the S\&P/TSX Composite Index during our event window, which extends from 1 July 2015 until 24 December 2015. Of the 244 Canadian stocks that remained in the S\&P/TSX Composite, we eliminate four stocks because of share splits or mergers that occurred during the event window.

The data includes all trade, order and quote messages with trading desk and broker IDs, and contains both publicly available fields and confidential regulatory markers. All event messages have onemillisecond time-stamp granularity. Trades are marked as buy- or sell-initiated. We focus on the continuous trading session and omit opening and closing auction trades. We also omit intentional broker cross trades that are not buy-side, since these are not related to prevailing liquidity conditions. ${ }^{15}$

\footnotetext{
${ }^{12}$ The Order Protection Rule requires marketplaces to establish, maintain and ensure compliance with written policies and procedures reasonably designed to prevent inferior-priced orders from "trading through," or executing, before immediately accessible, visible, better-priced limit orders.

${ }^{13}$ Post-only orders are limit orders that provide passive liquidity. These orders are rejected if immediately executable to prevent removing liquidity.

${ }^{14}$ The schedule of minimum order sizes during the sample period is at https://www.tsx.com/resource/en/1185/.

${ }^{15}$ We do include broker cross trades in our analysis of large, sequential buy-side trades since they are commonly used in that context (discussed in more detail below in Market quality and execution metrics).
} 
To construct liquidity measures for a control sample of US stocks, we use New York Stock Exchange (NYSE) trade-and-quote (TAQ) data with millisecond-level time-stamps. The dataset includes all trade prices and quantities, best bid and ask prices, and quantities at those prices aggregated across all trading venues that are part of the US Consolidated Tape system for all stocks that trade on these venues. ${ }^{16}$ This represents the majority of on-exchange trading in the US. Trades are not marked buy- and sell-initiated, so we assign trade direction using the Lee and Ready (1991) algorithm. We augment our data with daily closing prices and market capitalization using data from Bloomberg and the Center for Research in Securities Prices (CRSP).

We exclude Canadian holidays, and US holidays in those analyses with US control stocks. To improve identification, we also exclude a one-month transition period during which Alpha's market share was changing. The transition period runs from 16 September 2015, a week before the redesign during which Old Alpha's market share fell significantly, to 14 October 2015. New Alpha and Old Alpha's market shares are plotted in Figure 1. The figure shows the drop in Alpha's market share around the event date and subsequent stabilization. The excluded transition period is shown in grey and the event date with a vertical red line. We mark the transition period and event date similarly in other graphs in the paper. Varying the length of the transition period does not materially affect our findings.

$[* * *$ Figure 1 about here***]

\section{Trader classification}

IIROC data contains unique ID codes for the trading desk from which an order originated as well as the broker. We use a process as outlined in Devani et al. (2014) to classify trading desks into the following trader groups: high-frequency traders (HFTs), retail and buy side. The classification process is based on a supervised machine learning algorithm that incorporates a trading desk's attributes into an algorithm that is trained using verified instances for each category. Appendix 1 describes the classification procedure in more detail. To preserve trading desks' anonymity, IIROC further aggregates individual desks by broker. For instance, a buy-side broker observation would be an aggregation of the broker's buy-side trading desk clients.

Table 2 provides intuitively sensible summary statistics for the trader categories assigned by the classification algorithm. Measured by trade count, HFT trades comprise the largest percentage of trades (41.7\%), followed by buy side (38.2\%) and retail trades (9.4\%). ${ }^{17}$ HFTs are responsible for $91.9 \%$ of orders, and their order-to-trade ratio far exceeds that of the other groups ( 76.5 for HFT, followed by 4.8 for the buy side, and 1.8 for retail). On the other hand, $10.5 \%$ of retail trades are odd lot trades, while only $1.1 \%$ of buy-side and HFT trades fall into that category. Given the trading characteristics of each of the respective groups, these results confirm that the classification algorithm works well.

[***Table 2 about here***]

\footnotetext{
${ }^{16}$ Members of the US Consolidated Tape Association can be found at www.nyse.com/data/cta.

${ }^{17}$ The percentages in the first three rows do not add up to $100 \%$ because there are additional user groups that we do not report (sell side and specialist).
} 


\section{Heavy vs. light broker classification}

To analyze how outcomes and routing behaviour changed after the redesign of Alpha in the crosssection of traders, we divide buy-side broker-level observations and retail broker-level observations into two groups. For each trading desk type (retail or buy side), we compute the average volume share of each broker's total active trading volume (initiated by a marketable order) executed on Alpha in the post-period. These shares are shown in the bar graphs in Figure 2, which shows a high degree of heterogeneity among both buy side and retail. We rank broker types by the share routed to Alpha and designate the top half "heavy users" and the bottom half "light users" for both retail and buy side.

$$
\text { [***Figure } 2 \text { about here***] }
$$

\section{Market quality and execution metrics}

To measure market quality, we use the standard measures below. All measures that are calculated at the trade level are aggregated to the stock-day level using volume weights. Where appropriate, we compute a more granular volume-weighted average for each stock-day-broker type. All variables are winsorized at the $1^{\text {st }}$ and $99^{\text {th }}$ percentiles.

Depth (top of book) for a given venue is the sum of the respective depths at the national best bid and offer, which are computed as the daily average volume at top of book at the best bid (or offer), weighted by the length of time the venue is at the top of the book. ${ }^{18}$

Effective Spread is the relative difference, net of fees, between the trade price $P_{t}$ and the current value of the security, proxied by the mid-point of the spread at the time $t$ of the trade $V_{t}$. $D_{t}$ is an indicator variable which takes the value +1 when the buyer is active and -1 when the seller is active:

$$
E S_{t}=2 \times D_{t} \times \frac{\left(P_{t}-V_{t}\right)}{V_{t}} \times 10,000
$$

Price Impact is the relative difference between the future value of the security, proxied by the mid-point of the spread one second after a trade $V_{t+1 s}$ and the current value of the security $V_{t}$ :

$$
P I_{t}=D_{t} \times \frac{\left(V_{t+1 s}-V_{t}\right)}{V_{t}} \times 10,000
$$

Active Fill Rate is the fraction of marketable orders that execute; it is computed as the trade volume of marketable orders $\mathrm{Vol}_{t}$ over the order volume of marketable orders $\mathrm{Vol}_{0}{ }^{19}$

$$
A F R_{S}=\frac{\sum_{t=1}^{T} \operatorname{Vol}_{t}}{\sum_{o=1}^{O} \operatorname{Vol}_{o}}
$$

\footnotetext{
18 Intervals where the quote is locked or crossed are not included in the numerator or denominator.

${ }^{19}$ We deem an order marketable if it executes at the same millisecond it was entered into the order book by the exchange. Passive orders are excluded from the calculation; immediate-or-cancel orders are included.
} 
Execution Size is the number of shares reported to IIROC in a trade message. It measures the minimum size of two orders that are matched. It is reported for the active side of the trade.

IOC Size is the volume reported to IIROC for immediate-or-cancel (IOC) orders, a type of marketable order with the feature that any volume not immediately executed is cancelled rather than resting on the limit order book. It is a measure of the size of market orders.

Implementation shortfall measures the execution quality for a large, directional sequence of trades, as defined in Korajczyk and Murphy (2017). ${ }^{20}$ We will refer to these as "large trades." It compares a trader's actual cost of a large trade to its hypothetical cost if the whole trade could have been executed at the first trade price in the sequence.

$$
I S=\frac{D \times \sum_{n=1}^{N} p_{n} x_{n}}{p_{1} X}-1
$$

$D$ is an indicator variable that equals +1 for a buy trade and -1 for a sell trade. The large trade is made up of $N$ individual transactions, where $p_{n}$ is the price of transaction $n, x_{n}$ is the volume of transaction $n$, and $X$ is the total volume of the large trade.

Percent Spray is the percentage of orders submitted to multiple trading venues simultaneously as part of a large trade. It is the number of orders submitted with the same millisecond time-stamp on at least two trading venues divided by the total number of orders by a trader as part of a large trade. To account for the effect of the speed bump, we count orders submitted to New Alpha as simultaneous with those on other exchanges if they arrive in a window three milliseconds before or after other orders.

Order-to-trade ratio is the ratio of total orders submitted to total orders executed by a particular broker as part of a large trade. It measures how many orders are sent relative to those that were executed as part of a large trade.

\section{Summary statistics}

Table 3 presents market-wide summary statistics for the Canadian and US stocks in our sample, before and after the Alpha redesign. US market quality metrics are generally reflective of the US market being more liquid than the Canadian market. Canadian market quality metrics improve slightly from the preperiod to the post-period. Price impact is significantly lower, while depth and execution size are larger. Such an improvement is not evident in the US metrics; while some metrics such as depth improve, others such as effective spread deteriorate. We also note that the algorithm that matches US to Canadian stocks (discussed below) is working well: Canadian and US price and market capitalization are comparable in both periods.

\footnotetext{
${ }^{20}$ We identify large, directional trades as a sequence of unidirectional (all buying or all selling) trades from a particular buy-side trading desk in a single stock on a single trading day for a total value of $\$ 1$ million or more.
} 


\section{[***Table 3 about here***]}

We provide summary statistics for Alpha on its own in Table 4. Effective spread and price impact improve slightly after the redesign, consistent with a larger retail user presence on the venue. We also note that depth and execution size increase by 685 and 110 shares on average, driven by the bigger minimum order sizes associated with the post-only order type. Volume is lower in the period after the redesign.

\section{[***Table 4 about here***]}

Panel A of Table 5 lists summary statistics for both light and heavy buy-side users. There is a reduction in effective spread and price impact for both heavy and light users; the reduction is more noticeable for light users. Heavy users experience a reduction in the order-to-trade ratio and a larger increase in execution size and IOC order size relative to light users. The average implementation shortfall increases for the heavy users, but we notice that this is an extremely noisy measure (mean of 28.16 relative to a standard deviation of 86.57 in the post-period).

\section{[***Table 5 about here***]}

Panel B of Table 5 lists summary statistics for light and heavy retail users. The market quality measures in the pre-period are generally comparable to the post-period. At 34.5 shares, execution size for heavy users experiences a larger average increase than at 14.9 shares for light users, but both increases are highly statistically significant.

Table 6 shows summary statistics on the calculation of large trades. An interesting feature is that Alpha is still included in the execution of large trades: about $2 \%$ of the volume of liquidity-taking trades that were part of a large trade execute on Alpha (see Fraction Active New Alpha, post-period); liquidityproviding volume is substantially less at $0.6 \%$.

[***Table 6 about here ${ }^{* * *}$ ]

\section{Methodology}

\section{Canada vs. US: Difference in differences}

To estimate the effects of Alpha's changes on market liquidity, we use the standard difference-indifferences model. The methodology compares the change in market quality for stocks that were eligible for trading on Alpha before and after Alpha's redesign, relative to the market quality of a set of control stocks that were ineligible for trading on Alpha.

All stocks in the S\&P/TSX Composite Index are eligible for trading on Alpha in our sample. For this reason, our controls consist of US stocks included in the Russell 3000 Index and that were not interlisted on a Canadian exchange. We follow Davies and Kim (2009) to match each Canadian stock to a US stock 
based on average price and market capitalization in the pre-period. As Davies and Kim (2009) recommend, stocks are matched with replacement, so a US stock can act as a control for multiple Canadian stocks. Our matching criteria result in 207 unique US stocks matched to our sample of 240 unique Canadian stocks.

To estimate the effects of Alpha's changes, we use the following regression:

$$
\text { measure }_{i, t}=\beta \text { Canada }_{i} * \text { After }_{i, t}+\delta \text { After }_{i, t}+\gamma X_{i, t}+F E_{i}+\varepsilon_{i, t} \text {, }
$$

where $i$ is the index for the stock (including both treatments and controls), $t$ is the day index, measure is the liquidity or behavioural measure, Canada is a Canadian stock indicator, After is a post-redesign period indicator, $F E$ is a vector of stock fixed effects, $X$ is a vector of control variables, and $\varepsilon$ is the error term. We do not include the treatment indicator Canada on its own, because it is in the span of stockspecific fixed effects. The coefficient for the first difference between the pre- and post-periods is $\delta$. The coefficient of interest, the difference-in-differences estimate, is $\beta$. Standard errors are double-clustered by stock $i$ and date $t$.

We fit the model over two specifications, one with control variates and one without. To control for changes in liquidity associated with common liquidity determinants, we include volume, 1-hour volatility (the annualized standard deviation of log-returns of the mid-quote observed hourly) and closing volatility (the closing moving average of the annualized standard deviation of log-returns of the daily closing price), stock price, market capitalization, and a one-day-lagged version of the dependent variable. We repeat the analysis and estimate the effects on market quality for the following subsamples: maker-taker Canadian trading venues, inverted venues, buy-side traders and retail traders.

\section{Cross-sectional comparison}

Similar to the Canada-US comparison, we use a regression framework in the spirit of the difference-indifferences method to analyze how heavy users' transaction costs and routing behaviour changed following the redesign of Alpha, relative to light users. Since we do not have access to a suitable US control sample, we interpret these results as descriptive rather than causal, since the choice to use Alpha is endogenous and may affect outcomes on other trading venues. ${ }^{21}$

We estimate the following regression:

$$
\text { measure }_{i, t}=\beta \text { Heavy }_{i} * \text { After }_{i, t}+\delta \text { After }_{i, t}+\gamma X_{i, t}+F E_{i}+\varepsilon_{i, t} \text {, }
$$

where all indices and variables are as previously defined, except Heavy, a dummy variable for the heavy users group. The coefficient of interest again is $\beta$, which indicates the difference of the heavy users after Alpha's redesign relative to the light users. Standard errors are double-clustered by stock-group $i$, where $i$ enumerates all combinations of stocks and heavy or light users, and date $t$. We fit the model over two specifications, one with control variates and one without. The control variates are the same as in the previous specification. We note that not controlling for factors that influence the selection of Alpha

\footnotetext{
${ }^{21}$ Brogaard et al. (2015) perform a similar comparison when comparing entities that upgrade trading technology to those that do not.
} 
usage intensity may bias the coefficient estimates, but we consider the estimated signs to nonetheless be valid. A change in sign would have to presuppose that users choose Alpha despite experiencing worse execution quality there, which seems illogical, given that routing to Alpha (as an unprotected venue) is voluntary.

When comparing groups of traders, we compute market quality measures based on a given group's trading across all Canadian trading venues. We do this because it is common for traders to use multiple venues and looking at a single venue may therefore not capture equilibrium trading costs. Further, by measuring broker-types' trading costs on all venues, we are able to test whether costs between groups changed significantly.

\section{Results}

\section{Alpha does not segment retail flow away from remaining maker-taker venues}

Table 7 shows that the Alpha redesign changed Canadian equity venues' shares of retail order flow but did not lead to any additional segmentation of retail flow away from remaining (non-Alpha) maker-taker venues, in contrast to the findings in Chen et al. (2017). We examine two measures of retail flow segmentation: retail share, a venue's (or group of venues') market share of the total retail market; and retail component, the fraction of a venue's (or group of venues') total volume that is retail. In both cases, retail refers to liquidity-taking trades initiated by retail traders. From a market maker's perspective, a decrease in retail share indicates less absolute retail flow, and a decrease in retail fraction indicates less relative retail flow, with both measures indicating a potential for higher adverse selection costs. In the following analysis, we group venues based on their fee structure (maker-taker or inverted), and treat TMX Select and Alpha separately. We provide the retail share and retail component for each venue individually in Appendix 2.

After the Alpha redesign, the share of retail flow on the remaining maker-taker venues (including Chi-X and the TSX, Canada's largest exchange) increased from $68.6 \%$ in the pre-period to $76.3 \%$ in the postperiod (see Table 7 and Panel A of Figure 3). ${ }^{22}$ This increase runs counter to the notion that the Alpha redesign is increasing adverse selection on other venues by segmenting retail flow away from these venues. The likely drivers behind the increase are both the decommissioning of TMX Select and the effect of Alpha's redesign on the exchange's own market share: old Alpha had a $14.4 \%$ share of retail volume in the pre-period, while new Alpha has an $11.6 \%$ share in the post-period. The combined retail share of other inverted venues (not including new Alpha or TMX Select) shows no statistically significant change.

Table 7 and Panel B of Figure 3 show that the retail component on the remaining maker-taker venues increases from $11.3 \%$ to $12.6 \%$. A larger retail component is again inconsistent with Alpha segmenting away retail flow from maker-taker venues after the redesign. On the other hand, the retail component

\footnotetext{
${ }^{22}$ Excluding the Canadian Securities Exchange, a partially inverted venue, from the maker-taker group does not qualitatively change our results.
} 
on inverted venues declines from $16.3 \%$ to $14.6 \%$. Since the retail share of inverted venues does not change, the drop in the retail component is caused by adjustments in those venues' non-retail flow.

$$
\begin{aligned}
& {\left[{ }^{* * *} \text { Figure } 3 \text { about here }{ }^{* * *}\right]} \\
& {\left[* * * \text { Table } 7 \text { about here }{ }^{* * *}\right]}
\end{aligned}
$$

Despite changes in venues' retail shares and components, the Alpha redesign, including the speed bump, does not appear to act as a segmentation device. This is counter to the theoretical predictions in Brolley and Cimon (2017) and the empirical findings in Chen et al. (2017).

\section{Market-wide quality remains unchanged}

Consistent with Alpha not segmenting retail flow away from remaining maker-taker venues, we find that market quality has not been adversely affected by the Alpha redesign. We use four measures to examine changes in market quality: effective spread in basis points (bps), 1-second price impact, order book depth and execution size. We also show that this result is robust to subsampling different types of trader and venue types.

Panels A-D in Figure 4 graph market quality measures for the US and Canada and show that the US stocks provide a good control for Canadian liquidity. The Canadian measures co-move closely with their US counterparts, and, in the case of effective spread (Panel A), price impact (Panel B) and depth (Panel C), few differences between the pre- and post-periods are discernible in the figure.

\section{$\left[* * *\right.$ Figure 4 about here $\left.{ }^{* * *}\right]$}

Table 8 confirms the graphical evidence that no material changes in liquidity have taken place. Regression coefficient estimates of a post-Alpha redesign change in market quality in Canada (Row 1 , After ${ }^{*}$ (anada) are generally statistically insignificant and of small magnitude. There is weak evidence of an improvement in effective spreads for Canadian stocks in the regression specification that includes control variates; the improvement is around 0.6 basis points, compared with an unconditional sample mean of around 13.5 basis points and standard deviation of 12.9 basis points.

Execution size, unlike effective spread and price impact, shows a statistically significant improvement of 8.6 shares relative to the US (see column 6, Table 8). We attribute this change to minimum limit order size requirements imposed by Alpha. The improvement in execution size is also evident in Panel D of Figure 4, where the gap between the US execution size (blue line) and Canadian execution size (red line) narrows noticeably in the period after the Alpha redesign.

$$
\text { [***Table } 8 \text { about here }{ }^{* * *} \text { ] }
$$

Our results contrast with those in Chen et al. (2017), who find a mild deterioration in market liquidity after the Alpha redesign as well as increased market segmentation. These authors use the public Thomson Reuters Tick History dataset, which does not contain data from all venues and therefore only allows for a partial view into Canadian markets. On the other hand, our full regulatory dataset from IIROC contains the complete records of trades from all Canadian venues. In addition, our regulatory data 
contains granular trading desk IDs that allow us to assign market participant types. This means that we can measure the market segmentation in Canada by market participant type (such as retail) directly. Chen et al. (2016) need to proxy for segmentation with order dispersion, which assumes that brokers do not change the way they disperse orders after the redesign of Alpha. Our results show that this assumption is unrealistic, because the usage of sprayed orders by the buy side decreases after Alpha's redesign.

Table 9, Panel A shows no substantial changes in liquidity even after we subsample by type of trader. We focus on buy-side and retail investors since their trading costs represent those of end-investors. We find that the market-wide results in Table 8 are qualitatively similar to those broken down by types in Panel A of Table 9. Effective spreads and price impacts for both buy side and retail appear to narrow in the post-redesign period, though statistical significance is weak.

\section{$\left[* * *\right.$ Table 9 about here $\left.{ }^{* * *}\right]$}

The improvement in Canadian execution size (see Table 8) carries through to both retail and buy-side traders. Buy-side traders experience a 9.5 share improvement in execution size, while retail traders experience a 20.1 share improvement. ${ }^{23}$

Table 9, Panel B breaks market quality metrics down by venue type and confirms that market quality on both maker-taker and inverted venues is again largely unchanged. We exclude those trading venues that were directly affected by the Alpha redesign. We omit Old Alpha from the maker-taker trading venues, and New Alpha and the decommissioned TMX Select from the inverted trading venues. The effective spreads narrow on both types of venues by between 0.67 and 0.94 basis points, depending on regression specification and venue. In the case of inverted venues, we observe an increase in price impact, which is consistent with the lower retail component on these venues. However, this effect is not statistically significant. Overall, the magnitude of the change in the retail component is too small to appear to have any consistent impact on the market quality measures on inverted venues. We also note that the exclusion of Alpha and TMX Select eliminates the significance of the execution size increase. This suggests that the increase in execution size is in fact driven by Alpha's minimum order sizes, and not by other factors.

\section{Market quality and routing decisions in the cross-section: Traders adapt to Alpha}

We now provide insights into what motivates traders to route their orders to the new Alpha exchange. Table 10 shows that heavy users of Alpha (both buy side and retail) improve their fill rates and execution size, which may result in lower back-office costs. As before, our results are based on users' market-wide trading, and not just on their trading on Alpha alone. We again subsample by trader type and show that these benefits are in some cases traded off against slightly larger price impacts and effective spreads. Relative to light users, heavy buy-side users of Alpha experience a statistically significant improvement in their active execution size by 12.6 shares and their fill rate by 4.8 percentage points. There is mild evidence that these traders also experience an increase in price impact by 0.33 basis points and an

\footnotetext{
${ }^{23}$ The estimates for buy-side and retail brokers both exceed the unconditional estimate of 8.6 shares in Table 8 because additional broker classifications exist in the full dataset.
} 
increase in effective spread by 0.42 basis points (see also Panels $C$ and $D$ of Figure 5 ). We do not observe any statistically significant changes in buy-side traders' execution quality for large trades as measured by implementation shortfall (See Figure 5, Panel E, and Table 10).

Heavy retail users also experience an increase in execution size by 18.1 shares, and fill rates improve by 1.8 percentage points, relative to light users (see Table 10 and Panels $C$ and D, Figure 6). Table 10 shows that retail effective spreads and price impact do not change appreciably from the pre-period to the postperiod (see also Panels $A$ and $B$, Figure 6).

$$
\begin{aligned}
& {\left[{ }^{* * *} \text { Figure } 5 \text { about here }{ }^{* * *}\right]} \\
& {\left[{ }^{* * *} \text { Figure } 6 \text { about here }{ }^{* * *}\right]} \\
& {\left[{ }^{* *} \text { Table } 10 \text { about here }{ }^{* *}\right]}
\end{aligned}
$$

Table 11 shows that liquidity demanders appear to take advantage of the larger order sizes offered on Alpha by submitting larger market orders. We find a weakly significant increase in IOC order size by 63.4 shares in the post-period (see Table 11 and Panel A, Figure 7). The order-to-trade ratio for large trades by heavy buy-side users of Alpha, relative to the light users, significantly decreases in the post-period (see Table 11 and Panel B of Figure 7). This is consistent with large orders being executed in fewer trades, and it is also consistent with the increasing fill rate (see Table 11).

Routing behaviour is directly affected by the mechanics of the speed bump. We note that heavy users of Alpha significantly reduce the fraction of multi-venue spray orders by around 4 percentage points, relative to light users (see Panel C, Figure 7, and column 6, Table 11). Our results of users adapting their behaviour to the redesigned Alpha is consistent with prior work by Battalio, Corwin and Jennings (2016) and Malinova and Park (2015), who document that market participants adapt their behaviour in response to changes in the features of trading venues.

Our results on the reduced usage of spray order by the heavy users of Alpha also provide an alternative to a claim by Chen et al. (2017), who suggest that order flow with high adverse selection costs migrates away from Alpha and also worsens liquidity on non-Alpha trading venues. The authors measure the fraction of trades on a given venue that instantaneously move prices on other venues. They find fewer of these trades on Alpha relative to other trading venues and an increase on other venues following Alpha's redesign. Our findings suggest a different mechanism: users of Alpha submit fewer orders to multiple venues simultaneously, thereby likely reducing the number of their trades that instantaneously move prices across multiple venues.

$$
\begin{aligned}
& {\left[* * * \text { Figure } 7 \text { about here }{ }^{* * *}\right]} \\
& {\left[{ }^{* * *} \text { Table } 11 \text { about here }{ }^{* * *}\right]}
\end{aligned}
$$




\section{Conclusions}

We study the effects of the redesign of TSX Alpha, which imposed a speed bump as part of a larger set of changes. The Alpha redesign is an example of how trading venues attract order flow in a competitive environment by offering a bundle of features. We find that the changes made to Alpha did not impact market-wide liquidity: a difference-in-differences regression does not identify any significant impacts on effective spreads, price impact or quoted depth. These findings are robust to subsampling by exchange type and trader type. In addition, we document an improvement in average execution size for both buyside and retail users on Alpha, with the latter group experiencing the larger increase. We argue this is due to the minimum order size implemented for post-only orders on Alpha at the same time as the speed bump.

We find that outcomes for certain groups of end-investors changed following Alpha's redesign. Heavy users of Alpha experience higher fill rates and larger execution sizes, relative to light users. For buy-side investors, this is accompanied by higher price impacts and effective spreads, suggesting a willingness to accept a trade-off between marginal execution costs and operational cost. These changes in outcomes are accompanied by natural changes in behaviour consistent with a preference for higher fill rates and execution size on Alpha. Heavy users submit larger market orders and have lower order-to-trade ratios. They also submit fewer orders to multiple venues simultaneously, possibly because doing so improves their execution quality.

Other empirical work on Alpha's redesign finds that it harms Canadian market liquidity (Chen et al. 2016). Using public data, the paper finds effective spreads on other trading venues increased following Alpha's redesign and argues that this is due to Alpha attracting low adverse selection order flow away from these venues. Using the trading desk IDs available uniquely in our dataset, we test this mechanism by measuring the presence of retail trading on different venues as a proxy for low adverse selection flow. We find that low adverse selection order flow decreased on other inverted venues and increased on remaining maker-taker venues, including Canada's largest exchange, the TSX. These findings are consistent with the redesigned Alpha competing for order flow with other inverted venues, but not with the remaining maker-taker venues, and they provide an explanation for our finding that Alpha did not significantly affect market-wide liquidity in Canada.

From a policy perspective, our work demonstrates that certain concerns about speed bumps may not materialize. Prior to Alpha's launch in 2015, some Canadian market participants expressed concerns that Alpha would increase segmentation in Canada, favouring smaller retail orders at the expense of large institutional orders. ${ }^{24}$ Our findings show that Alpha is competing for order flow that is, in a sense, already segmented, and outcomes associated with increased segmentation are likely not applicable. The Canadian securities regulators acknowledged the possibility that Alpha's speed bump could negatively impact execution quality and fill rates if resting liquidity is cancelled while market orders are delayed by

\footnotetext{
${ }^{24}$ See the Ontario Securities Commission's summary of public comments: www.osc.gov.on.ca/documents/en/Marketplaces/alpha-exchange_20150421_noa-proposed-changes.pdf.
} 
the speed bump. ${ }^{25}$ However, we find that market-wide execution quality has not been negatively impacted by Alpha's redesign features. We note that it is difficult to generalize our findings beyond the context of Alpha's specific bundle of features and markets that are comparable to Canada's.

\footnotetext{
${ }^{25}$ See the Canadian Securities Administrators' notice on order-processing delays: www.osc.gov.on.ca/documents/en/Securities-Category2/csa_20140612_23-101_rfc-pro-amd-processingdelays.pdf.
} 


\section{References}

Battalio, R., Corwin, S., \& Jennings, R. (2016). Can Brokers Have It All? On the relation between maketake fees and limit order execution quality. Journal of Finance, 71(5), 2193-2238.

Brogaard, J., Hagströmer, B., Nordén, L., \& Riordan, R. (2015). Trading fast and slow: Colocation and liquidity. The Review of Financial Studies, 28(12), 3407-3443.

Brolley, M., \& Cimon, D. (2017). Order flow segmentation, liquidity and price discovery: The role of latency delays. Mimeo.

Biais, B., Foucault, T., \& Moinas, S. (2015). Equilibrium fast trading. Journal of Financial Economics, 116(2), 292-313.

Chen, H., Foley, S., Goldstein, M. A., \& Ruf, T. (2017). The value of a millisecond: Harnessing information in fast, fragmented markets.

Cimon, D. (2016). Broker routing decisions in limit order markets. Bank of Canada Staff Working Paper No. 2016-50.

Cortes, C., \& Vapnik, V. (1995). Support-vector networks. Machine learning, 20(3), 273-297.

Davies, R., \& Kim, S. (2009). Using matched samples to test for differences in trade execution costs. Journal of Financial Markets, 12(2), 173-202.

Devani, B., Tayal, A., Anderson, L., Zhou, D., Gomez, J., \& Taylor, G. W. (2014). Identifying trading groups-methodology and results. Discussion paper, IIROC Working Paper.

Foucault, T., Kozhan, R., \& Tham, W. W. (2017). Toxic arbitrage. The Review of Financial Studies, 30(4), 1053-1094.

Korajczyk, R., \& Murphy, D. (2017). High-frequency market making to large institutional trades.

Lee, C., \& Ready, M. J. (1991). Inferring trade direction from intraday data. The Journal of Finance, 46(2), 733-746.

Malinova, K., \& Park, A. (2015). Subsidizing liquidity: The impact of make/take fees on market quality. The Journal of Finance, 70(2), 509-536.

Menkveld, A. (2016). The economics of high-frequency trading: Taking stock. Annual Review of Financial Economics, Vol. 8, 1-24.

Mitchell, T. M. (1997). Machine learning. Burr Ridge, IL: McGraw Hill.

Shkilko, A., \& Sokolov, K. (2016). Every cloud has a silver lining: Fast trading, microwave connectivity and trading costs. 
Van Kervel, V. (2015). Competition for order flow with fast and slow traders. The Review of Financial Studies, 28(7), 2094-2127.

Zhu, H. (2013). Do dark pools harm price discovery? The Review of Financial Studies, 27(3), 747-789. 


\section{Appendix 1: Trader type assignment}

Trader IDs are classified with the process described in Devani et al. (2014). We start with a small, manually classified set of IIROC trading desk IDs known to belong to the respective user groups. We then train a machine learning algorithm to classify remaining IDs based on a set of observable characteristics which include, for example, the order-to-trade ratio, the percentage of trades involving a market maker, and the number of order and trade messages. We classify each ID into one of the following categories: high frequency trader, retail, specialist, institutional (sell side or buy side).

The machine learning algorithm takes a manually curated set of IDs of a given type as examples from which it identifies remaining IDs that show similar characteristics. The specific algorithm used was the Linear Support Vector Machine (SVM) (Cortes and Vapnik (1995)). To optimize the number of characteristics, we selected 16 , which provided maximum information gain and minimum correlation coefficients (Mitchell 1997).

Each ID is represented as a vector of the 16 features smoothed out by averaging over three months. To account for extremely high skewness and/or kurtosis and to make patterns more visible in the data, we applied a log transformation to any feature that had skewness $>5$ or kurtosis $>20^{4}$, as follows:

$$
\tilde{x}=\operatorname{sign}(x) \ln (1+|x|)
$$

where $\mathrm{x}$ is the original feature and $\tilde{x}$ is the transformed feature value. Following this transformation, all values are normalized to have unit standard deviation and zero mean.

The model was applied to the feature set for the period October 2014 to December 2015, resulting in daily classification for each ID for the full year of 2015. Traders are classified into a category for the entire study period by the mode of their daily categories. Finally, institutional IDs are classified as sell side or buy side using a regulatory label to identify whether a trade was on behalf of a client. 


\section{Appendix 2: Segmentation measures by individual venue}

In our main analysis of retail flow segmentation, we treat both the decommissioned TMX Select and Alpha separately, so as to hold the venues in the "maker-taker" and "inverted" groups constant. In addition, the inclusion of Alpha would produce a mechanistic change: even if there is no change at all in how much retail flow is routed to Alpha, the change in fee structure from maker-taker to inverted would produce a mechanistic increase in the inverted venues' retail share. Such a mechanistic change does not increase the adverse selection faced by market makers.

For completeness, Table A2.1 includes summary statistics on retail share and retail component for each venue individually.

Table A2.1: Summary statistics on retail share and fraction of retail across venues

\begin{tabular}{|c|c|c|c|c|c|c|c|c|c|c|c|c|}
\hline & \multicolumn{6}{|c|}{ Pre-period } & \multicolumn{5}{|c|}{ Post-period } & \multirow[t]{2}{*}{ Change } \\
\hline & & Mean & Std. & Min. & Max. & $\mathrm{N}$ & Mean & Std. & Min. & Max. & $\mathrm{N}$ & \\
\hline \multirow{11}{*}{ 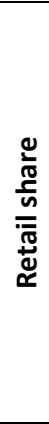 } & AQL & 0.005 & 0.001 & 0.002 & 0.009 & 51 & 0.010 & 0.003 & 0.004 & 0.017 & 48 & $0.005^{* * *}$ \\
\hline & AQN & 0.002 & 0.002 & 0.001 & 0.007 & 51 & 0.003 & 0.001 & 0.001 & 0.006 & 48 & $0.001^{* * *}$ \\
\hline & $\mathrm{CHX}$ & 0.131 & 0.009 & 0.107 & 0.147 & 51 & 0.174 & 0.010 & 0.149 & 0.201 & 48 & $0.043^{* * *}$ \\
\hline & CSE & 0.009 & 0.001 & 0.006 & 0.012 & 51 & 0.022 & 0.014 & 0.006 & 0.072 & 48 & $0.013^{* * *}$ \\
\hline & $\mathrm{CX} 2$ & 0.085 & 0.008 & 0.061 & 0.106 & 51 & 0.051 & 0.009 & 0.038 & 0.070 & 48 & $-0.034^{* * *}$ \\
\hline & LYX & 0.001 & 0.001 & 0.000 & 0.003 & 50 & 0.002 & 0.001 & 0.001 & 0.005 & 48 & $0.001^{* * *}$ \\
\hline & OMG & 0.035 & 0.008 & 0.023 & 0.058 & 50 & 0.067 & 0.008 & 0.048 & 0.086 & 48 & $0.031^{* * *}$ \\
\hline & TSE & 0.540 & 0.019 & 0.507 & 0.625 & 51 & 0.556 & 0.021 & 0.508 & 0.594 & 48 & $0.016^{* * *}$ \\
\hline & TMX Select & 0.048 & 0.009 & 0.027 & 0.078 & 51 & - & - & - & - & - & - \\
\hline & Old Alpha & 0.144 & 0.011 & 0.120 & 0.166 & 51 & - & - & - & - & - & - \\
\hline & New Alpha & - & - & - & - & - & 0.116 & 0.014 & 0.082 & 0.142 & 48 & - \\
\hline \multirow{11}{*}{ 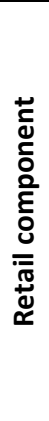 } & $\mathrm{AQL}$ & 0.166 & 0.035 & 0.117 & 0.245 & 51 & 0.165 & 0.041 & 0.098 & 0.288 & 48 & -0.001 \\
\hline & AQN & 0.143 & 0.051 & 0.059 & 0.299 & 51 & 0.130 & 0.023 & 0.089 & 0.208 & 48 & -0.013 \\
\hline & $\mathrm{CHX}$ & 0.099 & 0.013 & 0.074 & 0.132 & 51 & 0.127 & 0.015 & 0.097 & 0.175 & 48 & $0.028^{* * *}$ \\
\hline & CSE & 0.120 & 0.023 & 0.079 & 0.172 & 51 & 0.199 & 0.082 & 0.079 & 0.384 & 48 & $0.079^{* * *}$ \\
\hline & $\mathrm{CX} 2$ & 0.175 & 0.025 & 0.129 & 0.283 & 51 & 0.117 & 0.016 & 0.087 & 0.179 & 48 & $-0.058^{* * *}$ \\
\hline & LYX & 0.196 & 0.081 & 0.090 & 0.538 & 50 & 0.189 & 0.053 & 0.126 & 0.453 & 48 & -0.007 \\
\hline & OMG & 0.139 & 0.030 & 0.093 & 0.215 & 50 & 0.179 & 0.022 & 0.140 & 0.226 & 48 & $0.040^{* * *}$ \\
\hline & TSE & 0.117 & 0.022 & 0.084 & 0.233 & 51 & 0.123 & 0.014 & 0.100 & 0.167 & 48 & 0.006 \\
\hline & TMX Select & 0.188 & 0.038 & 0.142 & 0.320 & 51 & - & - & - & - & - & - \\
\hline & Old Alpha & 0.160 & 0.019 & 0.128 & 0.242 & 51 & - & - & - & - & - & - \\
\hline & New Alpha & - & - & - & - & - & 0.248 & 0.032 & 0.196 & 0.359 & 48 & - \\
\hline
\end{tabular}

This table shows summary statistics for retail share and retail component by trading venue type for a sample of Canadian stocks that were included in the TSX Composite in 2015. The left-hand side of the table (Pre-period) corresponds to the period before Alpha's redesign, from 1 July 2015 until 15 September 2015, while the right-hand side of the table (Post-period) corresponds to the period following Alpha's redesign, from 15 October 2015 until 24 December 2015. The upper half of the table (Retail share) shows volume share of retail liquidity-taking trades across trading venues, while the lower half of the table (Retail component) shows the fraction of trading volume from retail liquidity-taking trades for each trading venue. Observations are by date. Reported statistics are mean, standard deviation (Std.), minimum and maximum (Min. and Max.) and number of observations (N). Summary statistics are provided for all trading venues. *, **, and $* * *$ indicate statistical significance at the $10 \%, 5 \%$, and $1 \%$ level, respectively. 


\section{List of tables}

Table 1: Canadian equity trading venues

\begin{tabular}{llll}
\hline Trading venue Name & $\begin{array}{l}\text { Fee Structure } \\
\text { before 21 Sep 2015 }\end{array}$ & $\begin{array}{l}\text { Fee Structure after 21 } \\
\text { Sep 2015 }\end{array}$ & Features \\
\hline Alpha Exchange (Old Alpha) & Maker-taker & - & $\begin{array}{l}\text { Redesigned } \\
\text { (see New Alpha) }\end{array}$ \\
Aequitas NEO Exchange - Lit Book & Maker-taker & Maker-taker & \\
Aequitas NEO Exchange - NEO Book & Take-take & Take-take & Speed bump \\
Canadian Securities Exchange (CSE) & Maker-taker & Partially inverted ${ }^{26}$ & \\
Chi-X Canada ATS & Maker-taker & Maker-taker & Inverted \\
CX2 Canada ATS & Inverted & Take-take & Dark, broker cross only \\
Instinet Canada Cross & Take-take & Take-take & Dark, broker cross only \\
Liquidnet Canada & Take-take & Maker-taker & Dark \\
Lynx ATS & Maker-taker & Take-take & Decommissioned \\
Match Now & Take-take & Inverted & - \\
Omega ATS & Inverted & Maker-taker & \\
TMX Select & Maker-taker & Inverted & \\
Toronto Stock Exchange & - & & \\
TSX Alpha Exchange (New Alpha) & & & \\
\hline
\end{tabular}

This table shows fee structures and features of each of the 13 trading venues which were active during our study period. The fee structures are provided for the periods before and after the Alpha redesign and include Maker-taker, in which the passive (liquidity-providing) participant makes a rebate and the active (liquidity-taking) participant pays a fee; Inverted, in which the passive participant pays a fee and the active participant makes a rebate; and Take-take, in which both passive and active participants pay a fee. The "-" indicates a period in which the trading venue did not exist. The trading venues features include Dark, in which all orders on the trading venue are undisclosed; Speed bump, in which a delay is introduced between the receipt of a certain order and the execution of its instructions; and Broker cross only, where a trading venue accepts only intentional cross orders.

\footnotetext{
${ }^{26}$ In October 2015, CSE began to trade a list of highly-liquid securities using an active rebate fee structure and launched a guaranteed minimum-fill market-making program.
} 
Table 2: Summary statistics for trader classification

\begin{tabular}{lcccc}
\hline & Buy side & Retail & HFT & Other \\
\hline Percentage of Trades & 38.2 & 9.4 & 41.7 & 10.7 \\
Percentage of Volume & 40.8 & 22.9 & 21.6 & 14.7 \\
Percentage of Orders & 5.3 & 0.5 & 91.9 & 2.3 \\
Order-to-Trade Ratio & 4.8 & 1.8 & 76.5 & $\mathrm{n} / \mathrm{a}$ \\
Block Trade Volume Percent & 23.3 & 2.9 & 3.8 & $\mathrm{n} / \mathrm{a}$ \\
Odd Lot Percent & 1.1 & 10.5 & 1.1 & $\mathrm{n} / \mathrm{a}$ \\
Percentage of Overnight Orders & 10.9 & 82.6 & 0.0 & 6.5 \\
\hline
\end{tabular}

This table shows a selection of descriptive statistics for the classification of trader groups. The trader groups of interest are Buy side, Retail and HFT. Remaining trading desk groups are reported under Other. Reported statistics are Percentage of Trades, the number of trades by each trader group relative to the total; Percentage of Volume, the volume of trades by each trader group relative to the total volume; Percentage of Orders, the number of orders by each trader group relative to the total number of orders; Order-to-Trade Ratio, the ratio of the number of orders to the number of executed trades for each trader group; Block Trade Volume Percent, the percentage of each trader group's volume that was part of a block trade; Odd Lot Percent, the percentage of each trader group's number of trades that was an odd lot trade; and Percentage of Overnight Orders, the number of overnight orders by each trader group relative to the total number of overnight orders. 
Table 3: Summary statistics for Canadian and US stocks

\begin{tabular}{|c|c|c|c|c|c|c|c|c|c|c|c|c|}
\hline & \multicolumn{6}{|c|}{ Pre-period } & \multicolumn{5}{|c|}{ Post-period } & \multirow[t]{2}{*}{ Change } \\
\hline & & Mean & Std. & Min. & Max. & $\mathrm{N}$ & Mean & Std. & Min. & Max. & $\mathrm{N}$ & \\
\hline \multirow{9}{*}{ 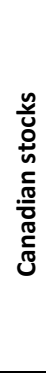 } & Eff. Spread & 13.53 & 12.88 & 1.52 & 85.53 & 12000 & 13.40 & 13.25 & 1.33 & 91.30 & 11280 & -0.13 \\
\hline & Price Impact & 5.50 & 4.29 & 0.72 & 30.38 & 12000 & 5.32 & 4.01 & 0.65 & 30.55 & 11280 & $-0.18^{* * *}$ \\
\hline & Execution Size & 166.0 & 94.9 & 82.36 & 883.70 & 12000 & 179.3 & 120.0 & 81.4 & 1042.6 & 11040 & $13.3^{* * *}$ \\
\hline & Volume & 1.07 & 1.45 & 0.02 & 10.63 & 12000 & 1.17 & 1.56 & 0.02 & 15.80 & 11280 & $0.10^{* * *}$ \\
\hline & Depth & 11412 & 33882 & 331 & 346765 & 12000 & 12226 & 32499 & 309 & 310224 & 11280 & 814.2 \\
\hline & $\begin{array}{l}\text { Volatility } \\
\text { (1 hour) }\end{array}$ & 12.44 & 8.41 & 2.12 & 104.12 & 12000 & 11.73 & 7.37 & 2.51 & 99.60 & 11280 & $-0.71^{* * *}$ \\
\hline & $\begin{array}{l}\text { Volatility } \\
\text { (closing) }\end{array}$ & 16.75 & 11.90 & 0.25 & 78.57 & 11280 & 16.68 & 11.75 & 1.68 & 82.28 & 11280 & -0.07 \\
\hline & Price & 31.62 & 41.45 & 1.30 & 346.32 & 12000 & 29.24 & 32.94 & 1.06 & 227.82 & 11280 & $-2.38^{* * *}$ \\
\hline & Market Cap. & 8.37 & 15.21 & 0.45 & 98.71 & 12000 & 7.79 & 13.16 & 0.29 & 77.59 & 11280 & $-0.57^{* *}$ \\
\hline \multirow{9}{*}{$\begin{array}{l}\frac{\tilde{u}}{u} \\
\stackrel{u}{u} \\
\tilde{D}\end{array}$} & $\begin{array}{l}\text { Effective } \\
\text { Spread }\end{array}$ & 10.35 & 10.48 & 1.44 & 91.17 & 12480 & 10.98 & 12.25 & 1.39 & 128.38 & 11272 & $0.62^{* * *}$ \\
\hline & Price Impact & 3.38 & 2.85 & 0.31 & 23.12 & 12480 & 3.35 & 3.06 & -0.49 & 23.46 & 11272 & -0.029 \\
\hline & Execution Size & 182.52 & 107.47 & 57.03 & 1103.38 & 12480 & 182.32 & 109.57 & 56.86 & 1441.20 & 11034 & -0.20 \\
\hline & Volume & 3.04 & 4.30 & 0.03 & 42.09 & 12480 & 3.07 & 4.21 & 0.03 & 45.44 & 11272 & 0.030 \\
\hline & Depth & 5956 & 14762 & 263 & 125726 & 12480 & 6652 & 17095 & 261 & 171521 & 11272 & $695.7^{* * *}$ \\
\hline & $\begin{array}{l}\text { Volatility } \\
\text { (1 hour) }\end{array}$ & 9.40 & 7.72 & 1.93 & 179.06 & 12480 & 9.48 & 5.81 & 1.25 & 47.30 & 11272 & 0.073 \\
\hline & $\begin{array}{l}\text { Volatility } \\
\text { (closing) }\end{array}$ & 13.85 & 10.63 & 0.00 & 82.23 & 11859 & 14.36 & 10.43 & 0.00 & 100.66 & 11272 & $0.506^{* * *}$ \\
\hline & Price & 31.90 & 42.10 & 1.65 & 339.50 & 12480 & 31.54 & 41.03 & 1.32 & 322.49 & 11272 & -0.35 \\
\hline & Market Cap. & 8.49 & 16.00 & 0.44 & 109.33 & 12480 & 8.42 & 16.19 & 0.29 & 111.07 & 11272 & -0.074 \\
\hline
\end{tabular}

This table shows summary statistics for market-wide market quality measures and controls used in the difference-in-differences panel regressions. The left-hand side of the table (Pre-period) corresponds to the period before Alpha's redesign, from 1 July 2015 until 15 September 2015, while the right-hand side of the table (Post-period) corresponds to the period following Alpha's redesign, from 15 October 2015 until 24 December 2015. The upper half of the table (Canadian stocks) corresponds to Canadian stocks that were included in the TSX Composite in 2015, while the lower half of the table (US stocks) corresponds to a matched sample of non-interlisted US stocks. Observations are on a stock-date level. Reported statistics are mean, standard deviation (Std.), minimum and maximum (Min. and Max.) and number of observations (N). Market quality variables are Effective Spread, the average difference between the trade price and mid-quote in basis points; Price Impact, the average difference between the mid-quote one second after a trade and at the time of trade in basis points; Execution Size, the average trading volume per trade executed; and Depth, the average volume available at the bid and ask. Control variables are Volume, daily trading volume; Volatility (1 hour), the daily volatility of the hourly mid-quote; Volatility (closing), the volatility of the previous five daily closing prices; Price, the daily closing price in dollars; and Market Cap, the daily closing market capitalization in millions. 
Table 4: Summary statistics on trading on Alpha pre- and post-redesign

\begin{tabular}{|c|c|c|c|c|c|c|}
\hline & & Mean & Std. & Min. & Max. & $\mathrm{N}$ \\
\hline \multirow{5}{*}{$\begin{array}{l}\frac{\pi}{c} \\
\frac{0}{2} \\
\frac{0}{4} \\
\frac{0}{0}\end{array}$} & Effective Spread & 14.74 & 15.03 & 1.25 & 167.03 & 12147 \\
\hline & Price Impact & 5.40 & 4.60 & -2.62 & 67.80 & 12147 \\
\hline & Execution Size & 150.34 & 112.40 & 73.68 & 3852.32 & 12147 \\
\hline & Depth & 1365 & 4559 & 0.00 & 159924 & 12147 \\
\hline & Volume & 0.12 & 0.21 & 0.00 & 5.92 & 12147 \\
\hline \multirow{5}{*}{$\begin{array}{l}\frac{\pi}{c} \\
\frac{2}{2} \\
\frac{3}{4} \\
\frac{3}{2} \\
2\end{array}$} & Effective Spread & 14.53 & 12.75 & 1.13 & 124.24 & 11406 \\
\hline & Price Impact & 3.07 & 3.37 & -14.92 & 67.92 & 11406 \\
\hline & Execution Size & 259.80 & 211.78 & 1.00 & 2688.72 & 11406 \\
\hline & Depth & 2050 & 6347 & 0.00 & 124305 & 11406 \\
\hline & Volume & 0.07 & 0.13 & 0.00 & 4.81 & 11406 \\
\hline
\end{tabular}

This table shows summary statistics for market quality measures on the Old Alpha and the redesigned Alpha ("New Alpha"). Observations are on a stock-date level. Reported statistics are mean, standard deviation (Std.), minimum and maximum (Min. and Max.) and number of observations ( $N$ ). Market quality variables are Effective Spread, the average difference between the trade price and mid-quote in basis points; Price Impact, the average difference between the mid-quote one second after a trade and at the time of trade in basis points; Execution Size, the average trading volume per trade executed; and Depth, the average volume available at the bid and ask. Volume is daily trading volume. 
Table 5: Summary statistics for trader groups

Panel A: Buy-side traders

\begin{tabular}{|c|c|c|c|c|c|c|c|c|c|c|c|c|}
\hline & \multicolumn{6}{|c|}{ Pre-period } & \multicolumn{5}{|c|}{ Post-period } & \multirow[t]{2}{*}{ Change } \\
\hline & & Mean & Std. & Min. & Max. & $\mathrm{N}$ & Mean & Std. & Min. & Max. & $\mathrm{N}$ & \\
\hline \multirow{8}{*}{ 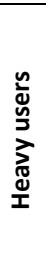 } & Effective Spread & 13.88 & 12.82 & 1.46 & 89.64 & 12342 & 13.82 & 13.14 & 1.38 & 101.71 & 11858 & -0.06 \\
\hline & Price Impact & 4.62 & 4.39 & -0.98 & 35.69 & 12342 & 4.54 & 4.29 & -0.03 & 37.65 & 11858 & -0.08 \\
\hline & Execution Size & 170.4 & 96.2 & 79.0 & 937.4 & 12342 & 189.0 & 121.5 & 82.7 & 1215.3 & 11858 & $18.6^{* * *}$ \\
\hline & Fill Rate & 0.69 & 0.13 & 0.23 & 0.97 & 12240 & 0.69 & 0.13 & 0.28 & 0.97 & 11760 & -0.00 \\
\hline & IOC Size & 785.5 & 1242.9 & 101.2 & 19431.7 & 12341 & 837.5 & 1313.8 & 103.7 & 20920.5 & 11858 & $51.96^{* *}$ \\
\hline & Order/Trade & 1.88 & 1.73 & 0.03 & 36.94 & 6136 & 1.65 & 1.27 & 0.02 & 15.06 & 5837 & $-0.23^{* * *}$ \\
\hline & Imp. Shortfall & 23.5 & 88.5 & -942.5 & 832.1 & 6136 & 28.1 & 86.5 & -485.1 & 724.0 & 5837 & $4.65^{* *}$ \\
\hline & Pct. Spray & 0.18 & 0.13 & 0.00 & 0.73 & 6136 & 0.09 & 009 & 0.00 & 0.58 & 5837 & $-0.09^{* * *}$ \\
\hline \multirow{8}{*}{ 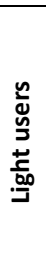 } & Effective Spread & 13.74 & 13.05 & 1.48 & 89.83 & 12342 & 13.39 & 13.44 & 1.24 & 96.42 & 11858 & $-0.35^{*}$ \\
\hline & Price Impact & 5.59 & 4.87 & 0.15 & 35.51 & 12342 & 5.25 & 4.44 & 0.24 & 33.79 & 11858 & $-0.34^{* * *}$ \\
\hline & Execution Size & 173.5 & 96.9 & 66.4 & 964.5 & 12342 & 183.4 & 123.6 & 77.7 & 1267.9 & 11858 & $9.9^{* * *}$ \\
\hline & Fill Rate & 0.74 & 0.10 & 0.37 & 1.00 & 12240 & 0.69 & 0.11 & 0.36 & 0.97 & 11760 & $-0.05^{* * *}$ \\
\hline & IOC Size & 549.2 & 748.4 & 100.0 & 20814.8 & 12342 & 551.6 & 678.6 & 108.3 & 11334.3 & 11858 & 2.47 \\
\hline & Order/Trade & 2.04 & 2.14 & 0.00 & 44.13 & 4902 & 2.20 & 2.51 & 0.01 & 63.16 & 4549 & $0.16^{* * *}$ \\
\hline & Imp. Shortfall & 22.19 & 102.83 & -828.46 & 812.02 & 4903 & 22.93 & 89.87 & -706.03 & 761.63 & 4550 & 0.747 \\
\hline & Pct. Spray & 0.13 & 0.12 & 0.00 & 0.80 & 4902 & 0.08 & 0.09 & 0.00 & 0.64 & 4549 & $-0.05^{* * *}$ \\
\hline
\end{tabular}

\section{Panel B: Retail traders}

\begin{tabular}{|c|c|c|c|c|c|c|c|c|c|c|c|c|}
\hline & \multicolumn{6}{|c|}{ Pre-period } & \multicolumn{5}{|c|}{ Post-period } & \multirow[t]{2}{*}{ Change } \\
\hline & & Mean & Std. & Min. & Max. & $\mathrm{N}$ & Mean & Std. & Min. & Max. & $\mathrm{N}$ & \\
\hline \multirow{4}{*}{ 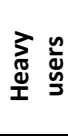 } & Effective Spread & 15.42 & 13.64 & 1.53 & 91.02 & 12342 & 15.56 & 14.13 & 1.52 & 103.66 & 11857 & 0.138 \\
\hline & Price Impact & 4.29 & 4.27 & -5.55 & 35.73 & 12342 & 4.00 & 3.92 & -3.29 & 30.28 & 11857 & $-0.29^{* * *}$ \\
\hline & Execution Size & 189.1 & 178.4 & 17.8 & 1546.2 & 12342 & 223.6 & 235.4 & 24.7 & 1918.7 & 11857 & $34.5^{* * *}$ \\
\hline & Fill Rate & 0.66 & 0.11 & 0.35 & 1.00 & 12240 & 0.67 & 0.10 & 0.35 & 1.00 & 11759 & $0.01^{* * *}$ \\
\hline \multirow{4}{*}{ 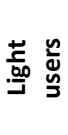 } & Effective Spread & 14.88 & 13.72 & 0.76 & 153.66 & 12167 & 14.94 & 14.17 & 1.22 & 101.84 & 11744 & 0.052 \\
\hline & Price Impact & 4.36 & 6.13 & -23.74 & 73.06 & 12167 & 4.21 & 5.57 & -14.61 & 47.14 & 11744 & $-0.151^{*}$ \\
\hline & Execution Size & 166.15 & 156.75 & 10.67 & 1347.94 & 12167 & 181.00 & 187.33 & 8.42 & 1777.8 & 11744 & $14.9^{* * *}$ \\
\hline & Fill Rate & 0.75 & 0.12 & 0.30 & 1.00 & 12002 & 0.74 & 0.13 & 0.35 & 1.00 & 11606 & $-0.01^{* * *}$ \\
\hline
\end{tabular}

This table shows summary statistics for variables used to compare heavy buy-side users of Alpha to light. The left-hand side of the table (Pre-period) corresponds to the period before Alpha's redesign, from 1 July 2015 until 15 September 2015. The righthand side of the table (Post-period) corresponds to the period following Alpha's redesign, from 15 October 2015 until 24 December 2015. The upper half of the table (Heavy users) corresponds to buy-side brokers with above-median Alpha volume for liquidity-taking orders, while the lower half of the table (Light users) to buy-side brokers with below-median Alpha volume for liquidity-taking orders. Observations are on a stock-date level. Reported statistics are mean, standard deviation (Std.), minimum and maximum (Min. and Max.) and number of observations ( $N$ ). Market quality variables are Effective Spread, the average difference between the trade price and mid-quote in basis points; Price Impact, the average difference between the mid-quote one second after a trade and at the time of trade in basis points; Execution Size, the average trading volume per trade executed; Fill Rate, the percentage of a liquidity demanding order which is filled; IOC Size, the size in shares of IOC orders; Order/Trade, the ratio of the number of child orders to the number of executed trades for a large trade; Implementation Shortfall, a measure of price impact for large trades; and Fraction Spray Orders, the percentage of orders routed to multiple venues simultaneously during large trades. 
Table 6: Summary statistics on calculation of large trades pre- and post-redesign

\begin{tabular}{|c|c|c|c|c|c|c|c|c|c|c|c|}
\hline \multicolumn{6}{|c|}{ Pre-period } & \multicolumn{5}{|c|}{ Post-period } & \multirow{2}{*}{$\begin{array}{l}\text { Change } \\
-534.9\end{array}$} \\
\hline Num. Trades & $\begin{array}{c}\text { Mean } \\
6922.0\end{array}$ & $\begin{array}{c}\text { Std. } \\
10660.0\end{array}$ & $\begin{array}{c}\text { Min. } \\
1.0\end{array}$ & $\begin{array}{c}\text { Max. } \\
103000\end{array}$ & $\begin{array}{c}\mathrm{N} \\
1800\end{array}$ & $\begin{array}{c}\text { Mean } \\
6387.1\end{array}$ & $\begin{array}{c}\text { Std. } \\
9259.6\end{array}$ & $\begin{array}{c}\text { Min. } \\
1.0\end{array}$ & $\begin{array}{c}\text { Max. } \\
88191.0\end{array}$ & $\begin{array}{c}\mathrm{N} \\
1862\end{array}$ & \\
\hline Volume & 2.019 & 3.12 & 0.002 & 40.021 & 1800 & 2.114 & 3.661 & 0.002 & 63.256 & 1862 & 0.095 \\
\hline Value & 56.16 & 96.28 & 1.002 & 1377.53 & 1800 & 60.64 & 105.50 & 1.001 & 1162.64 & 1862 & 4.48 \\
\hline Imp. Shortfall & 22.22 & 96.58 & -950.21 & 1380.82 & 1800 & 29.98 & 91.38 & -607.78 & 1401.24 & 1862 & $7.76^{*}$ \\
\hline Fraction Spray & 0.17 & 0.12 & 0.000 & 0.817 & 1800 & 0.10 & 0.091 & 0.000 & 0.796 & 1862 & $-0.07^{* * *}$ \\
\hline Order/Trade & 1.37 & 1.15 & 0.009 & 31.778 & 1800 & 1.35 & 0.942 & 0.019 & 13.872 & 1862 & -0.02 \\
\hline $\begin{array}{l}\text { Fraction } \\
\text { Passive New } \\
\text { Alpha }\end{array}$ & - & - & - & - & - & 0.006 & 0.022 & 0.000 & 0.215 & 1862 & - \\
\hline
\end{tabular}

This table shows measures for large trades, identified by directional trading from a particular trading desk on a stock-date with a value of $\$ 1$ million or more. The left-hand side of the table (Pre-period) corresponds to the period before Alpha's redesign, from 1 July 2015 until 15 September 2015, while the right-hand side of the table (Post-period) corresponds to the period following Alpha's redesign, from 15 October 2015 until 24 December 2015. Observations are averaged to the broker-date level. Reported statistics are mean, standard deviation (Std.), minimum and maximum (Min. and Max.) and number of observations (N). Measures are Number of Trades, number of trades in a large trade; Volume, total trading volume of large trades in millions of shares; Value, total trading value of large trades in millions of dollars; Implementation Shortfall, a measure of price impact for large trades; Fraction Spray Orders, the percentage of orders routed to multiple venues simultaneously; Order/Trade, the ratio of the number of child orders to the number of executed trades for a large trade; Fraction Active New Alpha, the volume share of liquidity-taking orders executed on Alpha in a large trade; and Fraction Passive New Alpha, the volume share of liquidity-providing orders executed on Alpha in a large trade. 
Table 7: Summary statistics on retail share and component of retail across venue types

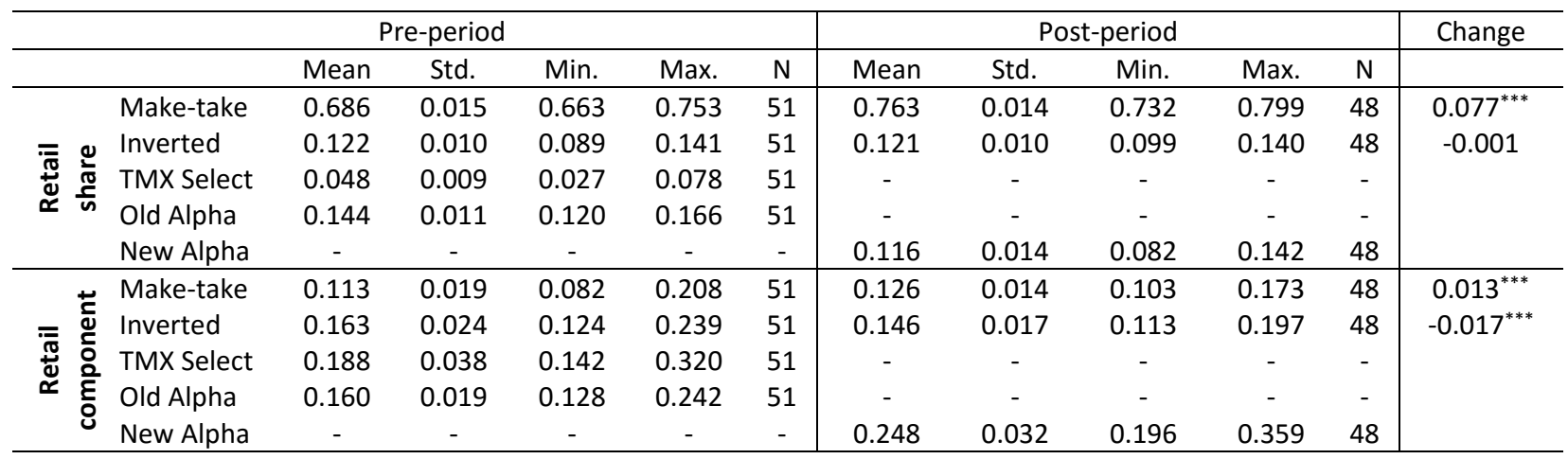

This table shows summary statistics for retail share and retail component by trading venue type for a sample of Canadian stocks that were included in the TSX Composite in 2015. The left-hand side of the table (Pre-period) corresponds to the period before Alpha's redesign, from 1 July 2015 until 15 September 2015, while the right-hand side of the table (Post-period) corresponds to the period following Alpha's redesign, from 15 October 2015 until 24 December 2015. The upper half of the table (Retail share) shows volume share of retail liquidity-taking trades across subsets of trading venues, while the lower half of the table (Retail component) shows the fraction of trading volume from retail liquidity-taking trades for each subset of trading venues.

Observations are by date. Reported statistics are mean, standard deviation (Std.), minimum and maximum (Min. and Max.) and number of observations $(N)$. Summary statistics are provided for four subsets of trading venues: Maker-taker, the trading venue subset with a maker-taker fee structure; Inverted, the trading venue subset with an inverted fee structure, Old Alpha, TMX Select and New Alpha. 
Table 8: Market-wide Canadian market quality measures vs. US

\begin{tabular}{|c|c|c|c|c|c|c|c|c|}
\hline & \multicolumn{2}{|c|}{ Effective Spread } & \multicolumn{2}{|c|}{ Price Impact } & \multicolumn{2}{|c|}{ Execution Size } & \multicolumn{2}{|c|}{ Depth } \\
\hline & (1) & (2) & (3) & (4) & (5) & (6) & (7) & (8) \\
\hline \multirow[t]{2}{*}{ After*Canada } & -0.764 & $-0.635^{*}$ & -0.155 & -0.101 & $13.48^{* * *}$ & $8.559^{* * *}$ & 117.4 & -212.2 \\
\hline & $(-1.63)$ & $(-1.70)$ & $(-1.05)$ & $(-0.90)$ & (3.24) & (3.04) & $(0.18)$ & $(-0.36)$ \\
\hline \multirow[t]{2}{*}{ After } & $0.629^{*}$ & $0.468^{*}$ & -0.0298 & -0.0398 & -0.163 & 0.117 & 696.7 & $657.5^{*}$ \\
\hline & (1.73) & $(1.71)$ & $(-0.30)$ & $(-0.65)$ & $(-0.05)$ & $(0.05)$ & (1.59) & $(1.76)$ \\
\hline \multirow[t]{2}{*}{ Volume } & & 0.00392 & & $-0.0513^{* * *}$ & & $8.730^{* * *}$ & & $342.5^{* * *}$ \\
\hline & & $(0.15)$ & & $(-3.95)$ & & (7.76) & & (3.48) \\
\hline \multirow{2}{*}{$\begin{array}{l}\text { Volatility } \\
\text { (1 hour) }\end{array}$} & & $0.169^{* * *}$ & & $0.0728^{* * *}$ & & -0.0787 & & $-84.75^{* * *}$ \\
\hline & & (7.73) & & (6.44) & & $(-0.75)$ & & $(-3.82)$ \\
\hline \multirow{2}{*}{$\begin{array}{l}\text { Volatility } \\
\text { (closing) }\end{array}$} & & 0.00383 & & -0.000281 & & $-0.150^{* * *}$ & & -18.26 \\
\hline & & $(0.48)$ & & $(-0.10)$ & & $(-3.05)$ & & $(-1.61)$ \\
\hline \multirow[t]{2}{*}{ Price } & & $-0.0436^{* * *}$ & & $-0.0123^{* * *}$ & & -0.0304 & & -14.92 \\
\hline & & $(-3.66)$ & & $(-4.14)$ & & $(-0.69)$ & & $(-1.64)$ \\
\hline \multirow[t]{2}{*}{ Market Cap. } & & 0.0128 & & 0.00288 & & 0.0728 & & -7.316 \\
\hline & & $(0.30)$ & & $(0.27)$ & & (0.35) & & $(-0.22)$ \\
\hline \multirow[t]{2}{*}{ Lag } & & $0.130^{* *}$ & & $0.275^{* * *}$ & & $0.284^{* * *}$ & & 0.151 \\
\hline & & $(2.22)$ & & $(10.42)$ & & (8.27) & & $(1.46)$ \\
\hline Observations & 47032 & 45691 & 47032 & 45691 & 46554 & 45213 & 47032 & 45691 \\
\hline$R^{2}$ & 0.900 & 0.917 & 0.798 & 0.839 & 0.847 & 0.891 & 0.912 & 0.919 \\
\hline
\end{tabular}

This table shows the results of a difference-in-differences panel regression of market-wide market quality measures before and after Alpha's redesign. Observations are on a stock-date level for Canadian stocks that were included in the TSX Composite in 2015, and a matched sample of US stocks that were ineligible to trade on Alpha. The sample period is from 1 July 2015 until 15 September 2015, and from 15 October 2015 until 24 December 2015. The table shows coefficient estimates for the differencein-differences estimator for four market quality variables: Effective Spread, the average difference between the trade price and mid-quote in basis points; Price Impact, the average difference between the mid-quote one second after a trade and at the time of trade in basis points; Execution Size, the average trading volume per trade executed; and Depth, the average volume available at the bid and ask. After is a dummy variable indicating the period after Alpha's redesign. Canada is a dummy variable indicating Canadian stocks. The coefficient of interest is their interaction, After*Canada. We include the following control variables in specifications (2), (4), (6) and (8): Volume, daily trading volume; Volatility (1 hour), the daily volatility of the hourly mid-quote; Volatility (closing), the volatility of the previous five daily closing prices; Price, the daily closing price in dollars; Market Cap, the daily closing market capitalization in millions; and Lag, the dependent market quality variable, lagged by one day. The regressions include stock-level fixed effects, standard errors are clustered by stock and date, and $t$-statistics are reported within parentheses. ${ }^{*}, *$, and $* * *$ indicate statistical significance at the $10 \%, 5 \%$, and $1 \%$ level, respectively. 
Table 9: Market quality results: Canada vs. US

Panel A: Selected trader types

\begin{tabular}{|c|c|c|c|c|c|c|c|}
\hline & & \multicolumn{2}{|c|}{ Effective Spread } & \multicolumn{2}{|c|}{ Price Impact } & \multicolumn{2}{|c|}{ Execution Size } \\
\hline & & (1) & (2) & (3) & (4) & (5) & (6) \\
\hline \multirow{7}{*}{$\begin{array}{l}\frac{0}{0} \\
\frac{0}{n} \\
⿱ 亠 乂 \\
0\end{array}$} & After*Canada & $-0.803^{*}$ & $-0.677^{*}$ & -0.168 & -0.122 & $13.66^{* * *}$ & $9.511^{* * *}$ \\
\hline & & $(-1.70)$ & $(-1.80)$ & $(-1.08)$ & $(-1.00)$ & (3.14) & (3.03) \\
\hline & After & $0.629^{*}$ & $0.469^{*}$ & -0.0298 & -0.0403 & -0.163 & 0.139 \\
\hline & & $(1.73)$ & $(1.70)$ & $(-0.28)$ & $(-0.62)$ & $(-0.05)$ & $(0.06)$ \\
\hline & Controls & No & Yes & No & Yes & No & Yes \\
\hline & Observations & 47032 & 45691 & 47032 & 45691 & 46554 & 45213 \\
\hline & $R^{2}$ & 0.895 & 0.912 & 0.753 & 0.795 & 0.818 & 0.858 \\
\hline \multirow{7}{*}{ 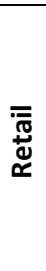 } & After*Canada & -0.469 & -0.370 & $-0.279^{*}$ & $-0.221^{*}$ & $30.20^{* * *}$ & $20.13^{* * *}$ \\
\hline & & $(-0.89)$ & $(-0.89)$ & $(-1.81)$ & $(-1.68)$ & $(5.33)$ & (5.59) \\
\hline & After & $0.629^{*}$ & $0.466^{*}$ & -0.0298 & -0.0417 & -0.163 & -0.0328 \\
\hline & & $(1.71)$ & $(1.70)$ & $(-0.30)$ & $(-0.56)$ & $(-0.06)$ & $(-0.02)$ \\
\hline & Controls & No & Yes & No & Yes & No & Yes \\
\hline & Observations & 47032 & 45691 & 47032 & 45691 & 46554 & 45213 \\
\hline & $R^{2}$ & 0.863 & 0.883 & 0.550 & 0.580 & 0.850 & 0.879 \\
\hline
\end{tabular}

Panel B: Selected venue types

\begin{tabular}{|c|c|c|c|c|c|c|c|c|c|}
\hline & & \multicolumn{2}{|c|}{ Effective Spread } & \multicolumn{2}{|c|}{ Price Impact } & \multicolumn{2}{|c|}{ Execution Size } & \multicolumn{2}{|c|}{ Depth } \\
\hline & & (1) & (2) & (3) & (4) & (5) & (6) & (7) & (8) \\
\hline \multirow{7}{*}{ 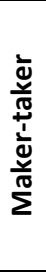 } & After*Canada & $-0.808^{*}$ & $-0.672^{*}$ & -0.141 & -0.0928 & $7.580^{*}$ & 3.843 & -280.3 & -525.8 \\
\hline & & $(-1.70)$ & $(-1.76)$ & $(-0.88)$ & $(-0.75)$ & $(1.82)$ & $(1.36)$ & $(-0.48)$ & $(-0.99)$ \\
\hline & After & $0.629^{*}$ & $0.463^{*}$ & -0.0298 & -0.0398 & -0.163 & 0.109 & 696.7 & 661.0* \\
\hline & & $(1.73)$ & $(1.70)$ & $(-0.30)$ & $(-0.65)$ & $(-0.05)$ & $(0.05)$ & $(1.59)$ & $(1.77)$ \\
\hline & Controls & No & Yes & No & Yes & No & Yes & No & Yes \\
\hline & Observations & 47032 & 45691 & 47032 & 45691 & 46554 & 45213 & 47032 & 45691 \\
\hline & $R^{2}$ & 0.906 & 0.923 & 0.820 & 0.856 & 0.852 & 0.892 & 0.909 & 0.916 \\
\hline \multirow{7}{*}{  } & After*Canada & $-0.937^{* *}$ & $-0.743^{* *}$ & 0.150 & 0.141 & 2.146 & 1.044 & -492.3 & -491.3 \\
\hline & & $(-2.08)$ & $(-2.04)$ & $(1.37)$ & $(1.62)$ & $(0.65)$ & $(0.42)$ & $(-1.14)$ & $(-1.55)$ \\
\hline & After & $0.629^{*}$ & $0.475^{*}$ & -0.0298 & -0.0407 & -0.163 & 0.0963 & 696.7 & $586.7^{*}$ \\
\hline & & (1.73) & (1.74) & $(-0.31)$ & $(-0.60)$ & $(-0.06)$ & $(0.04)$ & $(1.63)$ & (1.91) \\
\hline & Controls & No & Yes & No & Yes & No & Yes & No & Yes \\
\hline & Observations & 47031 & 45690 & 47031 & 45690 & 46553 & 45212 & 47031 & 45690 \\
\hline & $R^{2}$ & 0.868 & 0.888 & 0.681 & 0.724 & 0.839 & 0.881 & 0.910 & 0.930 \\
\hline
\end{tabular}

This table shows the results of a difference-in-differences panel regression of market-wide market quality measures before and after Alpha's redesign, restricted to selected trader types (Panel A) and venue types (Panel B). Buy side corresponds to a subsample of liquidity-taking trades by traders classified as buy side; Retail corresponds to a subsample of liquidity-taking trades by traders classified as retail. Maker-taker corresponds to a subsample from Canadian trading venues with maker-taker fee structures, excluding Old Alpha and TMX Select; Inverted corresponds to a subsample from inverted Canadian venues, excluding New Alpha.

Observations are on a stock-date level for a sample of Canadian stocks that were included in the TSX Composite in 2015, and a matched sample of US stocks that were ineligible to trade on Alpha. The sample period is from 1 July 2015 until 15 September 2015, and from 15 October 2015 until 24 December 2015. All variables are as defined in Table 8; Controls includes Volume, Volatility (1 hour), Volatility (closing), Price, Market Cap, and Lag. The regressions include stock-level fixed effects, standard errors are clustered by stock and date, and $t$-statistics are reported within parentheses. ${ }^{*}, * *$, and $* * *$ indicate statistical significance at the $10 \%, 5 \%$, and $1 \%$ level, respectively. 
Table 10: Market quality outcomes, heavy vs. light users

\begin{tabular}{|c|c|c|c|c|c|c|c|c|c|c|c|}
\hline & & \multicolumn{2}{|c|}{ Effective Spread } & \multicolumn{2}{|c|}{ Price Impact } & \multicolumn{2}{|c|}{ Execution Size } & \multicolumn{2}{|c|}{ Fill Rate } & \multicolumn{2}{|c|}{ Imp. Shortfall } \\
\hline & & (1) & $(2)$ & (3) & (4) & (5) & (6) & (7) & (8) & (9) & $(10)$ \\
\hline \multirow{6}{*}{$\begin{array}{l}\frac{0}{0} \\
\stackrel{0}{n} \\
\stackrel{0}{\infty}\end{array}$} & After*Heavy & 0.286 & $0.423^{*}$ & $0.256^{*}$ & $0.327^{* *}$ & $8.752^{* *}$ & $12.59^{* * *}$ & $0.0497^{* * *}$ & $0.0480^{* * *}$ & 2.828 & 0.553 \\
\hline & & $(0.75)$ & (1.84) & $(1.72)$ & $(2.44)$ & (2.49) & (4.31) & (7.75) & (8.16) & $(0.82)$ & $(0.14)$ \\
\hline & After & -0.345 & -0.256 & $-0.338^{*}$ & $-0.337^{* *}$ & $9.845^{* * *}$ & 3.045 & $-0.0499^{* * *}$ & $-0.0484^{* * *}$ & 2.111 & 2.255 \\
\hline & & $(-0.99)$ & $(-1.25)$ & $(-1.92)$ & $(-2.43)$ & (3.35) & (1.37) & $(-8.30)$ & $(-9.94)$ & $(0.79)$ & $(0.72)$ \\
\hline & Controls & No & Yes & No & Yes & No & Yes & No & Yes & No & Yes \\
\hline & Observations & 48400 & 47674 & 48400 & 47674 & 48400 & 47674 & 48000 & 47280 & 21426 & 14587 \\
\hline \multirow{7}{*}{ 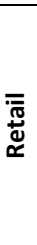 } & After*Heavy & 0.111 & 0.0563 & -0.127 & -0.162 & $19.52^{* * *}$ & $18.11^{* * *}$ & $0.0160^{* * *}$ & $0.0178^{* * *}$ & & \\
\hline & & $(0.26)$ & $(0.17)$ & $(-0.82)$ & $(-1.06)$ & (3.31) & (3.73) & $(3.06)$ & (3.87) & & \\
\hline & After & 0.0266 & 0.0419 & -0.158 & -0.130 & $15.01^{* * *}$ & $7.776^{* * *}$ & $-0.0109^{* *}$ & $-0.0120^{* * *}$ & & \\
\hline & & $(0.06)$ & $(0.14)$ & $(-0.86)$ & $(-0.93)$ & $(3.86)$ & $(2.83)$ & $(-2.51)$ & $(-3.17)$ & & \\
\hline & Controls & No & Yes & No & Yes & No & Yes & No & Yes & & \\
\hline & Observations & 48110 & 47384 & 48110 & 47384 & 48110 & 47384 & 47607 & 46787 & & \\
\hline & $R^{2}$ & 0.775 & 0.813 & 0.291 & 0.313 & 0.809 & 0.831 & 0.316 & 0.329 & & \\
\hline
\end{tabular}

This table shows the results of a panel regression of market quality measures before and after Alpha's redesign, comparing heavy users of Alpha to light users. The upper half of the table (Buy side) corresponds to a subsample of Canadian data from liquidity-taking trades by traders classified as buy side, while the lower half of the table (Retail) corresponds to a subsample of Canadian data from liquidity-taking trades by traders classified as retail. Observations are on a stock-date level for a sample of Canadian stocks that were included in the TSX Composite in 2015. The sample period is from 1 July 2015 until 15 September 2015, and from 15 October 2015 until 24 December 2015. The table shows coefficient estimates for five market quality measures: Effective Spread, the average difference between the trade price and mid-quote in basis points; Price Impact, the average difference between the mid-quote one second after a trade and the time of trade in basis points; Execution Size, the average trading volume per trade executed; Fill Rate, the percentage of a liquidity-demanding order which is filled; and Implementation Shortfall, a measure of price impact for block trades. After is a dummy variable indicating the period after Alpha's redesign (launch date 21 September 2015). Heavy is a dummy variable indicating trading activity through a broker who was identified as a heavy user of Alpha in the post-period. The coefficient of interest is their interaction, After*Heavy. We include the following control variables in specifications (2), (4), (6), (8) and (10) but supress them for brevity: Volume, daily trading volume; Volatility (1 hour), the daily volatility of the hourly mid-quote; Volatility (closing), the volatility of the previous five daily closing prices; Price, the daily closing price in dollars; Market Cap, the daily closing market capitalization in millions; and Lag, the dependent market quality outcome, lagged by one day. The regressions include stock-group-level fixed effects, standard errors are clustered by stock and date, and $t$-statistics are reported within parentheses. $*, * *$, and $* * *$ indicate statistical significance at the $10 \%, 5 \%$, and $1 \%$ level, respectively. 
Table 11: Trading behaviour for buy side, heavy vs. light users

\begin{tabular}{lcccccc}
\hline & \multicolumn{2}{c}{ IOC Size } & \multicolumn{2}{c}{ Order-to-Trade Ratio } & \multicolumn{2}{c}{ Fraction Spray } \\
\hline & $(1)$ & $(2)$ & $(3)$ & $(4)$ & $(5)$ & $(6)$ \\
\hline After*Heavy & 49.52 & $63.43^{*}$ & $-0.361^{* * *}$ & $-0.399^{* * *}$ & $-0.0349^{* * *}$ & $-0.0428^{* * *}$ \\
& $(1.33)$ & $(1.74)$ & $(-3.51)$ & $(-3.32)$ & $(-5.10)$ & $(-6.03)$ \\
After & 2.472 & -24.05 & 0.138 & $0.196^{* *}$ & $-0.0510^{* * *}$ & $-0.0432^{* * *}$ \\
& $(0.13)$ & $(-1.33)$ & $(1.54)$ & $(2.08)$ & $(-9.02)$ & $(-7.31)$ \\
Controls & No & Yes & No & Yes & No & Yes \\
\hline Observations & 48399 & 47672 & 21424 & 14586 & 21424 & 14586 \\
$R^{2}$ & 0.174 & 0.210 & 0.288 & 0.308 & 0.172 & 0.206 \\
\hline
\end{tabular}

This table shows the results of a panel regression of measures of trading behaviour before and after Alpha's redesign, comparing heavy users of Alpha to light users, for traders classified as buy side. Observations are on a stock-date level for a sample of Canadian stocks that were included in the TSX Composite in 2015. The sample period is from 1 July 2015 until 15 September 2015, and from 15 October 2015 until 24 December 2015. The following measures are included: IOC Size, the size in shares of IOC orders; Order/Trade, the ratio of the number of child orders to the number of executed trades for a large trade; and Fraction Spray Orders, the percentage of orders routed to multiple venues simultaneously as part of a large trade. After is a dummy variable indicating the period after Alpha's redesign (launch date 21 September 2015). Heavy is a dummy variable indicating trading activity through a broker who was identified as a heavy user of Alpha in the post-period. The coefficient of interest is their interaction, After*Heavy. We include the following control variables in specifications (2), (4), (6), (8) and (10) but supress their output for brevity: Volume, daily trading volume; Volatility (1 hour), the daily volatility of the hourly midquote; Volatility (closing), the volatility of the previous five daily closing prices; Price, the daily closing price in dollars; Market $\mathrm{Cap}$, the daily closing market capitalization in millions; and Lag, the dependent market quality outcome, lagged by one day. The regressions include stock-group-level fixed effects, standard errors are clustered by stock and date, and $t$-statistics are reported within parentheses. ${ }^{*}, * *$, and $* * *$ indicate statistical significance at the $10 \%, 5 \%$, and $1 \%$ level, respectively. 


\section{List of figures}

Figure 1: Alpha's market share from 1 July 2015 until 24 December 2015

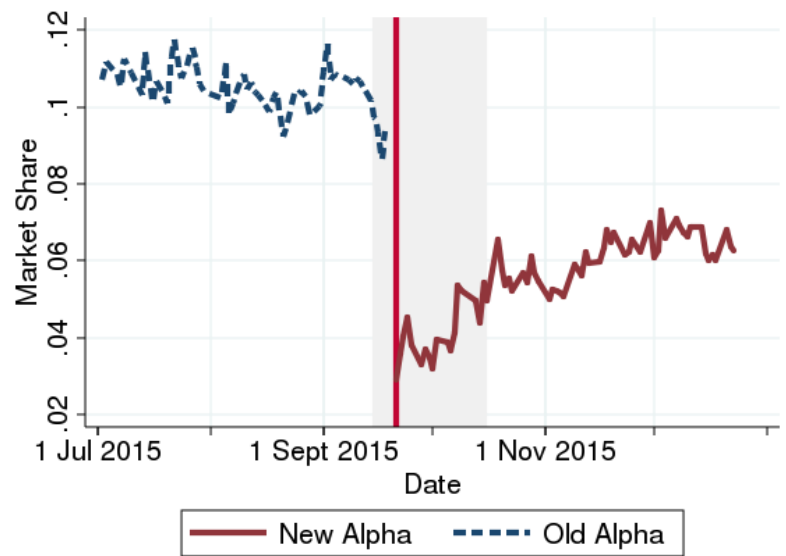

This figure shows Alpha's market share (of volume) for Canadian stocks which were included in the TSX Composite in 2015. The blue, dashed line marked Old Alpha is the average market share prior to the launch date. The red, solid line marked New Alpha is the average market share following the launch date. The pre-period is 1 July to 15 September 2015, and the post-period is 15 October to 24 December 2015. The transition period, which we exclude from our study, is between 16 September and 14 October and is indicated by the grey area. The redesign date is indicated by the vertical red line and corresponds to 21 September 2015. 
Figure 2: Active Alpha use in post-period by broker type
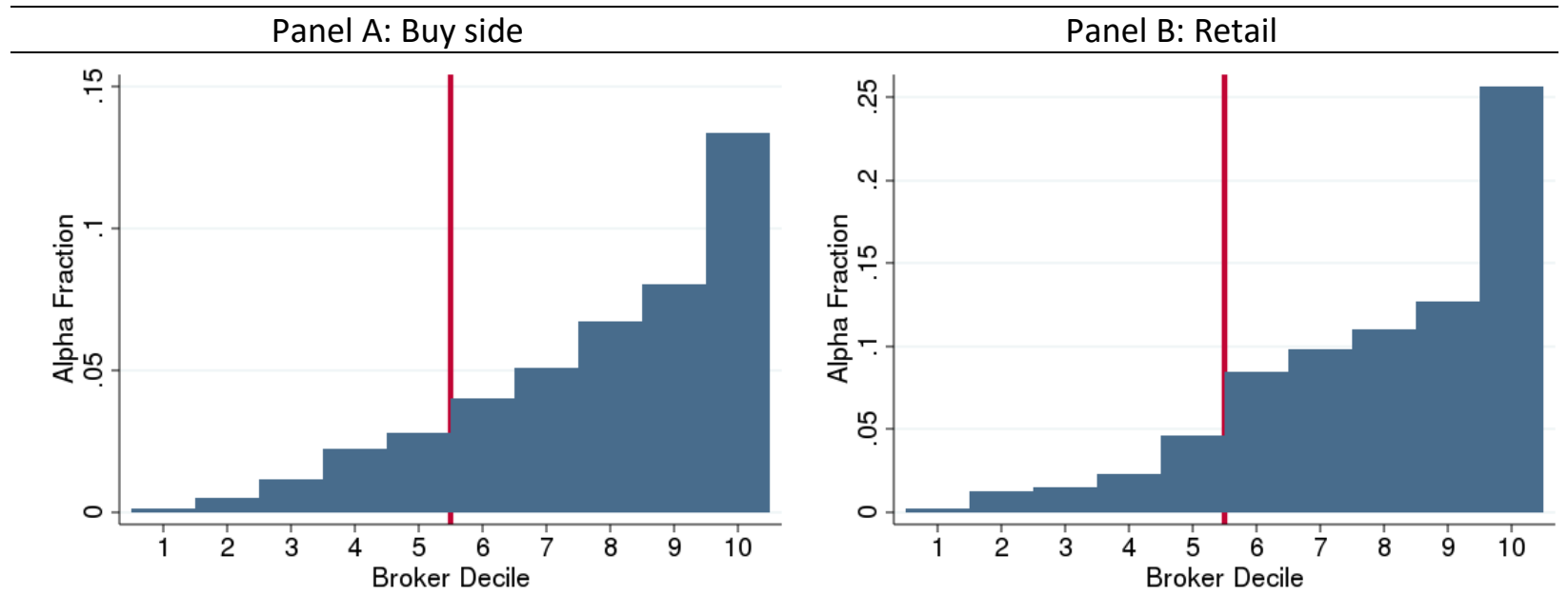

This figure shows how brokers are divided into heavy and light users. For each broker's trading on behalf of buy side (retail), the fraction of that broker's buy-side (retail) trading volume which took place on the redesigned Alpha, relative to all the broker's buy-side (retail) trading volume on all venues in the post-period (Alpha Fraction), is calculated. The brokers are ranked by the Alpha fraction; brokers with greater-than-median rank are classified as heavy users. Panel A shows the Alpha fraction for the brokers that traded on behalf of buy side by decile, and Panel B shows the Alpha fraction for the brokers that traded on behalf of retail by decile. The solid red vertical line divides the brokers into heavy users and light users at the sample median. 
Figure 3: Retail share and retail component across venue types

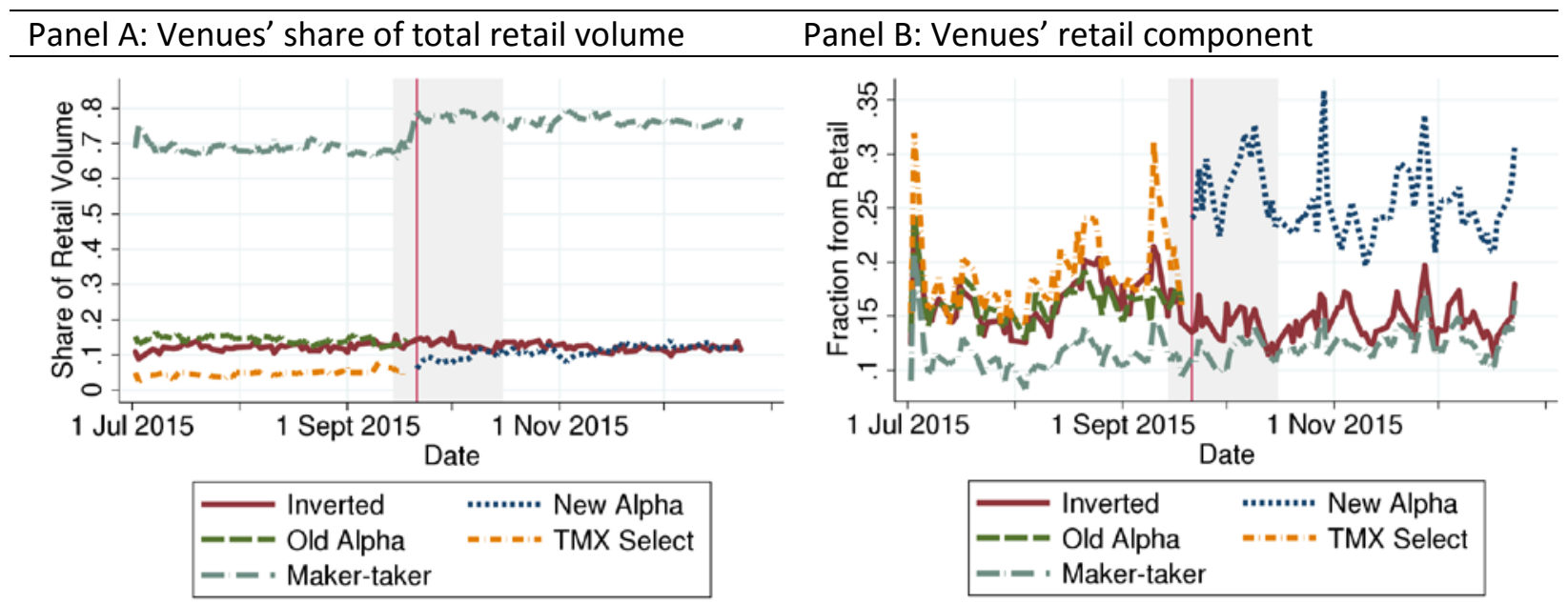

This figure shows retail share and retail component by trading venue subset. Panel A shows Share of Retail Volume, the share of liquidity-taking retail trading across the subset of trading venues. The total retail share is 1. Panel B shows Retail Component, the fraction of liquidity-taking trading volume on a trading venue subset that is retail. Five trading venue subsets are identified: Maker-taker, venues with a maker-taker trading structure; Inverted, venues with an inverted trading structure; New Alpha; Old Alpha; and TMX Select. Observations are by date for Canadian stocks that were included in the TSX Composite in 2015. The preperiod is 1 July to 15 September 2015, and the post-period is 15 October to 24 December 2015. The transitional period, which we exclude in our study, is between 16 September and 14 October and is indicated by the grey area. 
Figure 4: US-Canada market quality measures for all trades
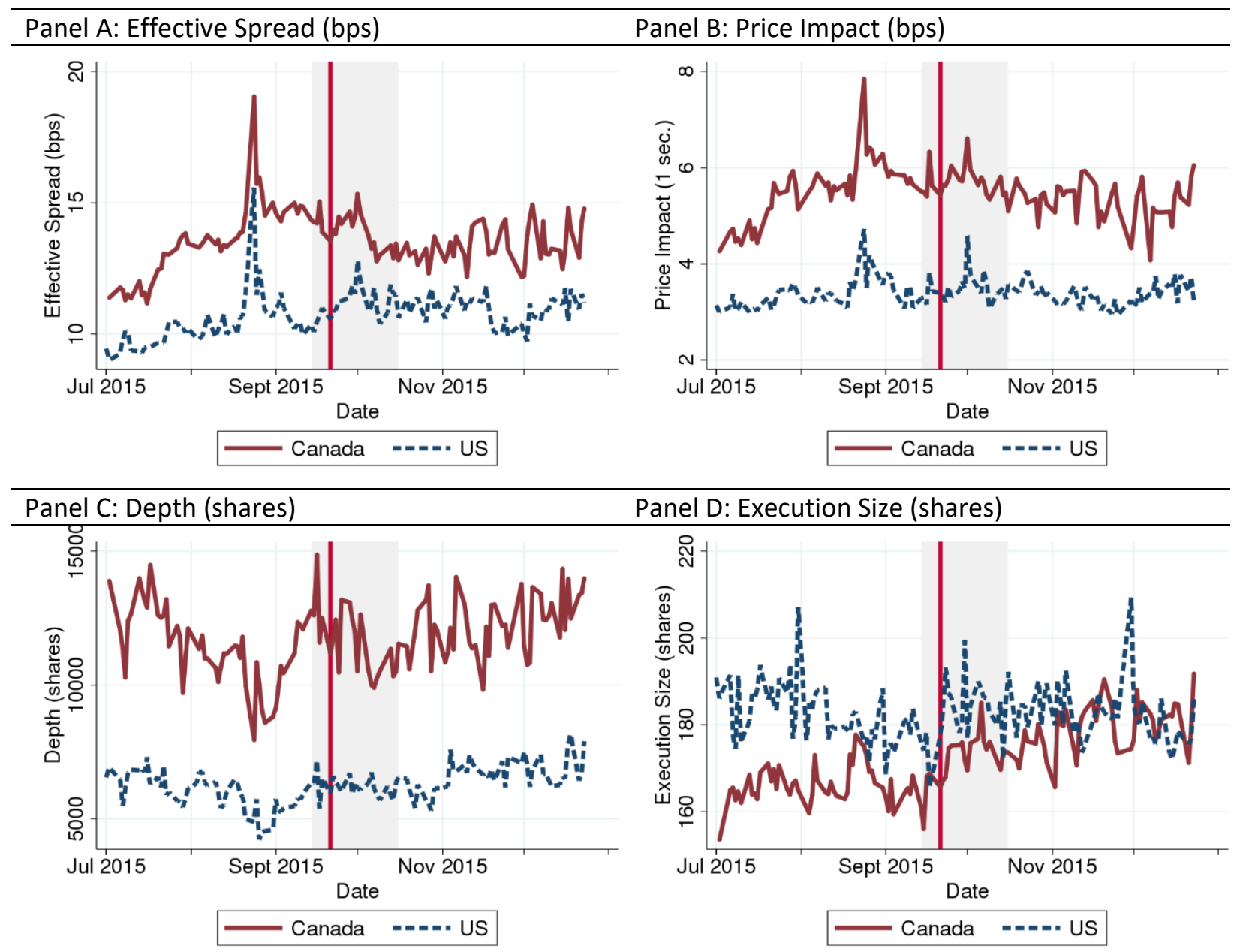

This figure shows average market-wide market quality measures for a sample of Canadian and US stocks. The red, solid line marked Canada is an average of measures for stocks which were included in the TSX Composite in 2015. The blue, dashed line marked US is an average of measures for a matched sample of US stocks that were ineligible to trade on Alpha. The pre-period is 1 July to 15 September 2015, and the post-period is 15 October to 24 December 2015. The transition period, which we exclude in our study, is between 16 September and 14 October and is indicated by the grey area. Panels A, B, C and D correspond to four market quality variables of interest: Effective Spread, the average difference between the trade price and mid-quote in basis points; Price Impact, the average difference between the mid-quote one second after a trade and at the time of trade in basis points; Execution Size, the average trading volume per trade executed; and Depth, the average volume available at the bid and ask. 
Figure 5: Market quality outcomes, heavy vs. light users, buy side

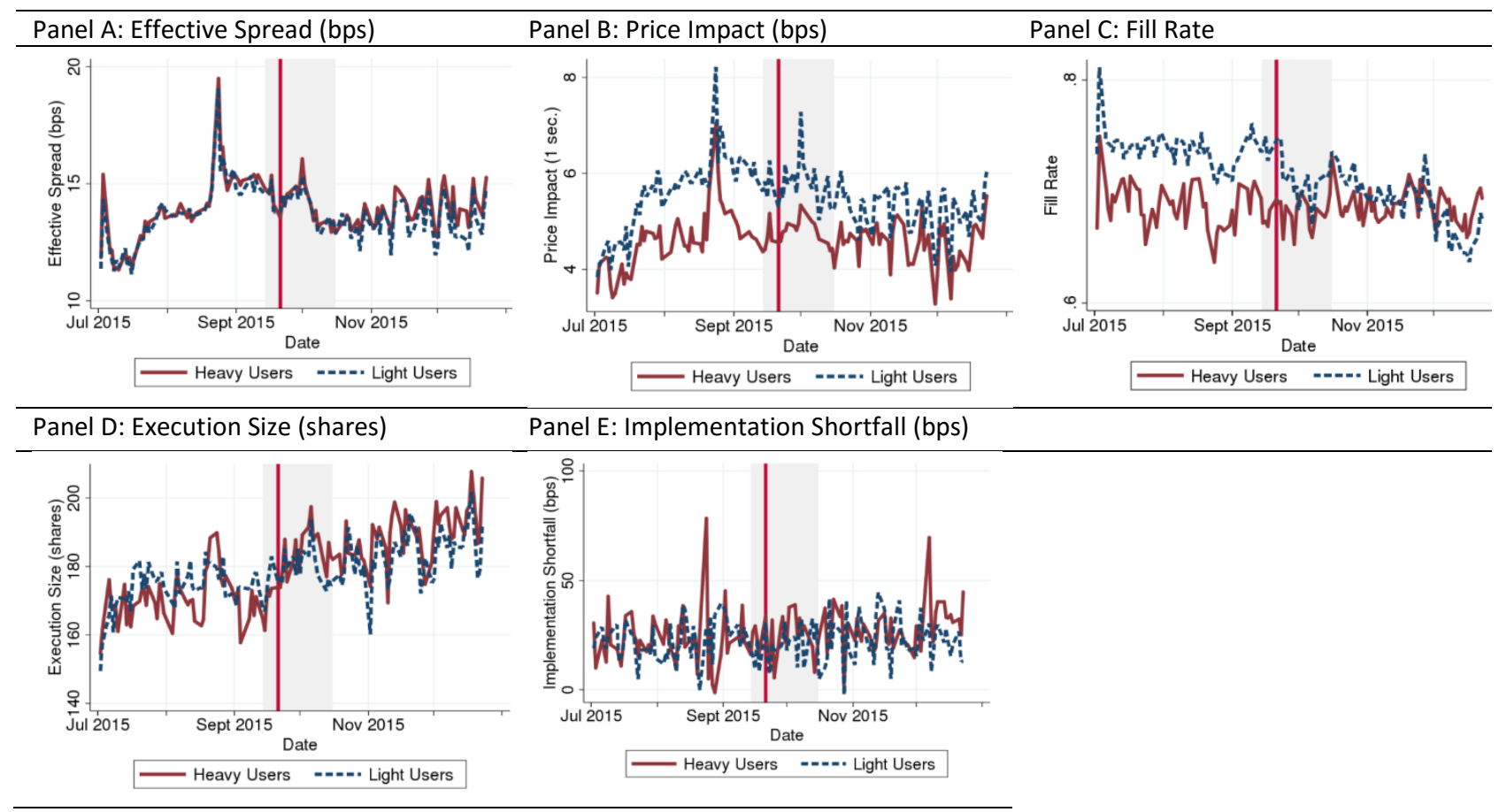

This figure shows average market quality outcomes for traders classified as buy side for trading in Canadian stocks which were included in the TSX Composite in 2015. The red, solid line marked Heavy Users is an average of outcomes for trading activity through a broker who was identified as a heavy user of Alpha post-redesign. The blue, dashed line marked Light Users is an average of outcomes for trading activity through a broker who was identified as a light user of Alpha post-redesign. The preperiod is 1 July to 15 September 2015, and the post-period is 15 October to 24 December 2015. The transition period, which we exclude in our study, is between 16 September and 14 October and is indicated by the grey area. Panels A, B, C, D and E correspond to five market quality outcomes of interest: Effective Spread, the average difference between the trade price and mid-quote in basis points; Price Impact, the average difference between the mid-quote one second after a trade and at the time of trade in basis points; Fill Rate, the percentage of a liquidity demanding order which is filled; Execution Size, the average trading volume per trade executed; and Implementation Shortfall, a measure of price impact for large trades. 
Figure 6: Market quality outcomes, heavy vs. light users, retail
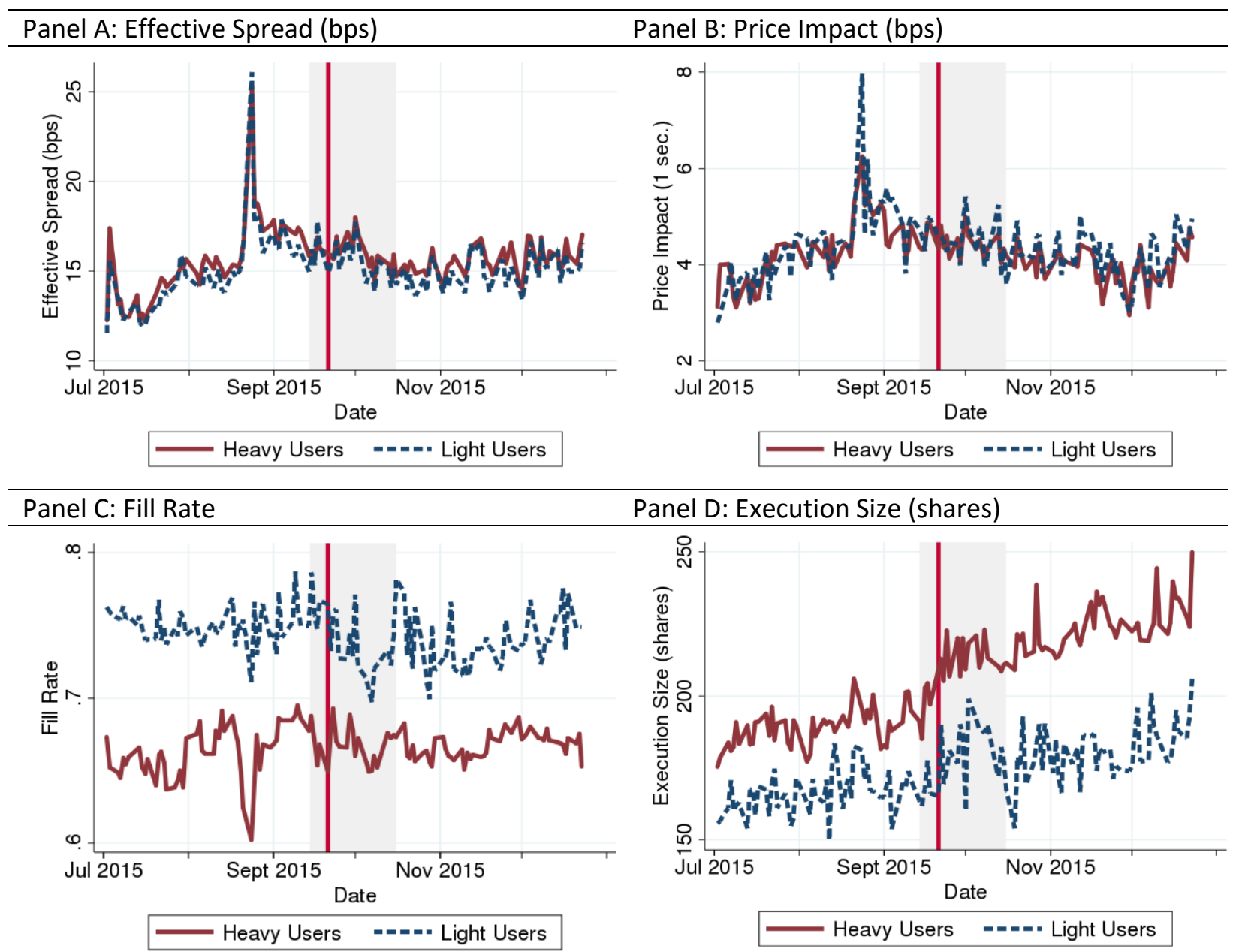

Panel D: Execution Size (shares)

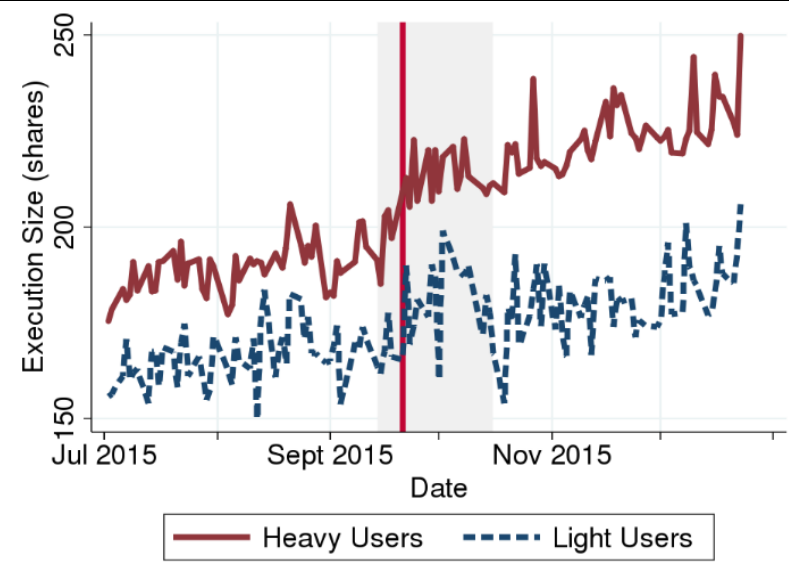

This figure shows average market quality outcomes for traders classified as retail for trading in Canadian stocks which were included in the TSX Composite in 2015. The red, solid line marked Heavy Users is an average of outcomes for trading activity through a broker who was identified as a heavy user of Alpha post-redesign. The blue, dashed line marked Light Users is an average of outcomes for trading activity through a broker who was identified as a light user of Alpha post-redesign. The preperiod is 1 July to 15 September 2015, and the post-period is 15 October to 24 December 2015. The transition period, which we exclude in our study, is between 16 September and 14 October and is indicated by the grey area. Panels A, B, C and D correspond to four market quality outcomes of interest: Effective Spread, the average difference between the trade price and mid-quote in basis points; Price Impact, the average difference between the mid-quote one second after a trade and at the time of trade in basis points; Fill Rate, the percentage of a liquidity demanding order which is filled; and Execution Size, the average trading volume per trade executed. 
Figure 7: Order entry behaviour for buy side, heavy vs. light users
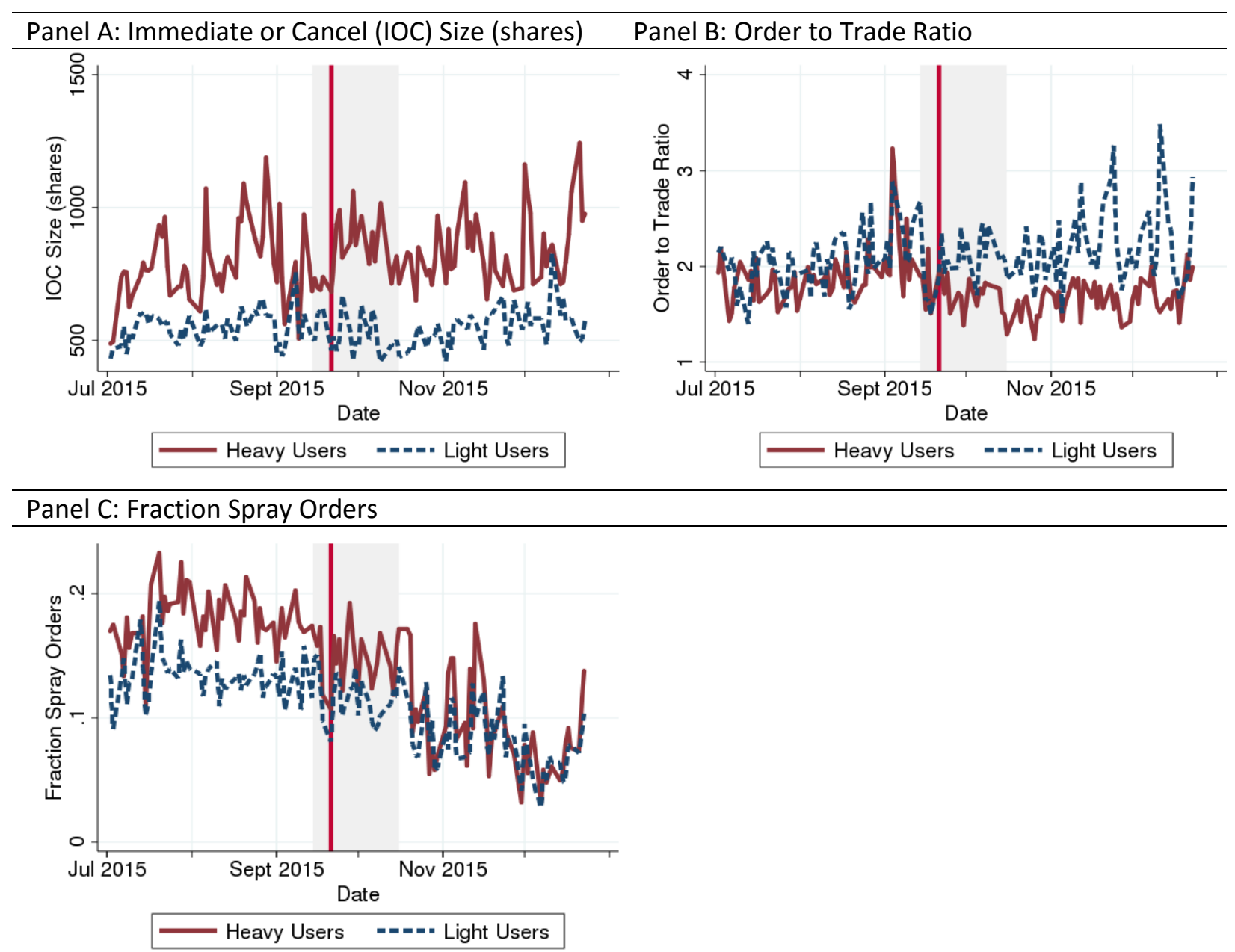

This figure shows trading behavior for traders classified as buy side for trading in Canadian stocks which were included in the TSX Composite in 2015. The red, solid line marked Heavy Users is an average of measures for trading activity through a broker who was identified as a heavy buy-side user of Alpha post-redesign. The blue, dashed line marked Light Users is an average of measures for trading activity through a broker who was identified as a light buy-side user of Alpha post-redesign. The preperiod is 1 July to 15 September 2015, and the post-period is 15 October to 24 December 2015. The transition period, which we exclude in our study, is between 16 September and 14 October and is indicated by the grey area. Panels A, B and C correspond to three market quality variables of interest: IOC Size, the size in shares of IOC orders; Order to Trade Ratio, the ratio of the number of child orders to the number of executed trades for a large trade; and Fraction Spray Orders, the percentage of sprayrouted orders for large trades. 